\title{
A novel approach to thermal storage of direct steam generation solar power
}

\section{systems through two-step heat discharge ${ }^{1}$}

Jing $\mathrm{Li}^{\mathrm{a}}$, Guangtao $\mathrm{Gao}^{\mathrm{b}}$, Cagri Kutlu ${ }^{\mathrm{a}}$, Keliang $\mathrm{Liu}^{\mathrm{c}}$, Gang Pei ${ }^{\mathrm{b}, *}$, Yuehong Su${ }^{\mathrm{a}, \dagger}$, Jie Ji ${ }^{\text {b }}$, Saffa Riffat ${ }^{\mathrm{a}}$

${ }^{a}$ Department of Architecture and Built Environment, University of Nottingham, University Park, Nottingham, NG7 2RD, UK

${ }^{b}$ Department of Thermal Science and Energy Engineering, University of Science and Technology of China, 96 Jinzhai Road, Hefei,230026,China

${ }^{c}$ Advanced Product Division, Hangzhou Boiler Group, 1216 Danonggang Road, Hangzhou, 310021, China.

*Corresponding author. Tel.: +86 055163607367 ; fax: +86 055163607367.

E-mail address: peigang@ustc.edu.cn

${ }^{\dagger}$ Corresponding author. Tel.: +44 011584 67872; fax: +44 01158467872.

E-mail address: yuehong.su@nottingham.ac.uk

Abstract: Steam accumulators are the only commercial solution for heat storage of direct steam generation (DSG) solar thermal power plants. Current accumulators have low storage capacity as the turbine suffers from inefficient off-design operation during heat discharge, thereby restricting the development of DSG technology. This work

\footnotetext{
1 The short version of the paper was presented at ICAE2017, Aug 21-24, Cardiff, UK. This paper is a substantial extension of the short version of the conference paper.
} 
presents a novel approach to solving this problem by using two-stage accumulators and steam-organic Rankine cycles (RC-ORC). The system involves unique two-step heat discharge. Heat is initially released via water vaporization in a high temperature accumulator (HTA) to drive the RC-ORC, leading to an HTA temperature drop of approximately $30^{\circ} \mathrm{C}$. Water at a reduced temperature then flows from the HTA to a low temperature accumulator through a heat exchanger and the heat is used only to drive the ORC. Water temperature further drops by $130-190^{\circ} \mathrm{C}$. The fundamentals of the system are illustrated. A comparison with the conventional DSG system is conducted at a nominal power of $10 \mathrm{MW}$ with an accumulator volume of $2500 \mathrm{~m}^{3}$. Thermodynamic performance of the system is investigated. The equivalent payback period $(E P P)$ regarding the use of the second step heat discharge is estimated. Results indicate that the second step heat discharge can increase the storage capacity by $460 \%$, with an EPP of less than 5 years in most cases. Overall, the proposed solution improves the cost-effectiveness of the DSG system.

Keywords: two-step heat discharge; two-stage accumulators; two-stage steam-organic Rankine cycles; direct steam generation; wet steam turbine; equivalent payback period

\section{Introduction}

Direct steam generation (DSG) technology is an option for future cost reduction in concentrating solar power (CSP) systems. The DSG solar power systems are 
commercial. Many plants are operational, as shown in Table 1 [1], and numerous plants are under construction. Compared with other commercial CSP systems, a DSG system eliminates the oil-water or molten salt-steam heat exchanger, and is more environmentally friendly. Common collectors in DSG applications include parabolic trough collectors (PTCs), linear Fresnel collectors (LFCs) and heliostats. PTCs have been used in Project Direct Solar Steam [2], 8 MWht Abengoa Solar plant [3] and 5 MWe plant [4]. LFCs are a subgroup of linear concentrators using linear receivers and reflectors. LFCs use relatively low-cost, mass-produced flat glass mirrors as reflectors, and have desirable characteristics in the DSG system. The receiver is fixed and expensive ball joints can be avoided. The main heat flux comes from the bottom of the tube to enhance water boiling, and the temperature differences around its circumference can be diminished. The technical requirements for heat collection are reduced. Heliostats can provide high temperature superheated steam $\left(>450^{\circ} \mathrm{C}\right)$, thereby leading to increased power generation efficiencies. A solar tower power plant has a good degree of flexibility in terms of plant construction, because heliostats do not need to be positioned on an even surface [5].

Thermal storage is a crucial issue in CSP plants. Storage methods based on phase change materials (PCMs), concretes and molten salts have been proposed for the DSG systems. By placing encapsulation of the PCM in small containers enclosed in water, a sufficient heat transfer rate can be achieved and steam can be generated at a constant pressure. The integration also facilitates an increase in volumetric storage capacity [6]. An alternative design allows water/steam flow through a number of tubes immersed in 
the PCM, thus producing superheated steam at the exit [7]. A concrete system connected to a steam accumulator or the encapsulated PCMs is advantageous in high temperature applications for heating up the steam to a superheated state [8-9]. The combination of a sensible heat storage unit for preheating, a latent one using PCMs for evaporation, and a sensible one for superheating has attracted a considerable amount of interest [1011]. The three-stage design can reduce the heat transfer irreversibility and pressure drop in the charge and discharge processes.

Notably, the only commercial heat storage solution for the DSG plants are steam accumulators [12]. Owing to the rapid evaporation and condensation of water/steam under non-equilibrium conditions, steam accumulators possess fast reaction times and high discharge rates, thereby making them promising option for reducing the effect of fluctuating irradiance on power generation of solar thermal systems [6]. Steam accumulators may be integrated into the power plants through several methods, as shown in Fig.1 [13-14]. These methods include storage at constant pressure, nearly constant pressure, and sliding pressure. Flashing occurs inside the vessel for the sliding pressure storage, which is also called Ruth's accumulator. This kind of storage has been adopted in the Puerto Errado 1, Puerto Errado 2, Planta Solar 10 and Planta Solar 20 plants. The schematic diagrams of Planta Solar 10 and Puerto Errado 2 are displayed in Fig.2 [15-16]. For example, in Planta Solar 10, when heat is required to cover a period of limited insolation, steam is generated at variable pressure, from $4 \mathrm{MPa}$ to the minimum pressure allowed by the system to run the turbine at a $50 \%$ partial load [15]. By using steam accumulators, saturated steam can be directly generated for power 
conversion. The superheated section in the solar field, which is usually a challenging part of the control systems [17-18], is thus avoided. On the other hand, wet steam turbines with inherent high technical requirements and inefficiencies are necessary [19].

The wet steam turbines would benefit from being integrated with an organic Rankine cycle (ORC) for several reasons. First, as a bottoming cycle the ORC decreases the overall pressure ratio of steam turbines. A conventional steam Rankine cycle (RC) comprises high pressure (HP) and low pressure (LP) turbines. The LP turbine can be omitted when the ORC is used. The steam quality at the HP turbine outlet can be increased by elevating the ORC operating temperature. Second, a dry organic fluid, unlike water, goes into superheated state when expanding from a saturated vapor state, thereby offering a more efficient expansion. An ORC turbine is typically a dry turbine which can operate without the need for superheating at the inlet, and has an isentropic efficiency of up to $90 \%$ [20]. According to the Baumann rule [21-22], 1\% average moisture causes approximately $1 \%$ drop in turbine efficiency. Therefore the ORC turbine is likely to have a higher efficiency than a wet steam turbine. Third, the ORC technology has reached a considerable degree of maturity in biomass and geothermal power plants, and has great potential in the solar thermal power generation application. Studies have been conducted on solar ORCs with respect to the cost [23], dynamic behavior [24], configuration [25-26] and application [27]. The storage concepts related to steam accumulators should be applicable in principle to solar ORC systems [28-29]. Plants have been built as shown in Table $2[1,30]$.

At present, the main problem of the DSG technology is the lack of economically 
competitive long time storage [12,31]. Steam accumulators are high pressure vessels and could be extremely expensive at large volumes. The conventional accumulators operate according to the fundamental principles in the heat discharge process as follows: (1) Water is vaporized by reducing the pressure of the saturated liquid, and the steam flows into the turbine for power conversion.

(2) The supplied steam during discharge has a lower pressure than the nominal condition.

(3) The final temperature drop of water in the accumulators is small to avoid inefficient power generation, thereby resulting in a limited storage capacity.

In the Planta Solar 10 plant, a discharge pressure from $4 \mathrm{MPa}$ at $100 \%$ rated load to that at $50 \%$ load should be accompanied by a temperature drop from approximately 250 to $212^{\circ} \mathrm{C}$ in accordance with the ellipse law, as further discussed in Sections 3.1.2 and 4.2. In the Khi Solar One plant, the pressure falls from $11 \mathrm{MPa}$ to $3.5 \mathrm{MPa}$ and $2.2 \mathrm{MPa}$ during discharge to generate steam with $50{ }^{\circ} \mathrm{C}$ of superheat. The average temperature drop of water in the accumulator should be less than $60^{\circ} \mathrm{C}$. Moreover, it takes 10.5 hours of discharging time to produce the power equivalent to that generated in three-hour nominal operation [31].

This work aims to develop a novel technology for the prolonged, cost-effective storage of DSG systems which allows a significantly larger water temperature drop, as well as a good level of thermal efficiency and power output. This goal is realized by two-step heat discharge in a configuration of two-stage accumulators and steam-organic Rankine cycles (RC-ORC). In the first step, heat discharge occurs in the high 
temperature accumulator (HTA), which is similarly to conventional DSG plants. The energy is used to drive the RC-ORC. This step ceases when the total power output or heat-to-power efficiency falls below the nominal output or efficiency of the sole ORC. In the second step, the water at the reduced temperature gradually moves from the HTA to the low temperature accumulator (LTA) through a heat exchanger. The heat is utilized only to drive the ORC.

To the best of the authors' knowledge, it is the first time that the turbine-driven RC has been combined with the ORC in the DSG solar thermal power systems. The indirect PTC-CSP system using the RC-ORC has been investigated [32-33]. Given a steam turbine inlet pressure and temperature of $12.0 \mathrm{MPa}$ and $390{ }^{\circ} \mathrm{C}$, the system does not have superiority over a solar RC system operating at a vacuum condensing pressure. The RC-ORC does not perform better than the RC except in cold climates, in which case the RC suffers from high specific volumes and exhaust loss at low condensation temperatures [34-35]. As a bottoming cycle, ORC has not attracted much interest in the conventional thermal oil and molten salt-related CSP systems, probably because the steam at the inlet of the turbine is highly superheated and can expand at a low pressure without causing trouble to the device by droplets. However, the ORC is beneficial for DSG systems, as mentioned previously.

Moreover, the two-step heat discharge is unique. This heat discharge is possible because of the RC-ORC. Water is the working fluid of the RC in the first step, whereas it acts only as the heat transfer fluid for the ORC in the second step. The discharge process differs from that of conventional steam accumulators and two-tank storage 
using molten salts. For conventional steam accumulators, the heat discharge is accompanied with steam generation. For the two-tank molten salt storage, vaporization during discharge is not expected.

The structure of the work is shown in Fig.3. The proposed solution is illustrated in the following section. A comparison with the commercial DSG systems is carried out. The effect of the LTA on storage capacity is evaluated. The equivalent payback period with respect to the use of the second step heat discharge is analyzed. Finally, the cost advantages are outlined.

\section{Description of the approach applied in the CSP system}

Fig.4 shows the innovative DSG system using two-stage accumulators and Rankine cycles. Steam is directly generated in the solar field. The topping cycle is the RC, which mainly comprises steam turbine, condenser (HX1), pumps (P1 and P4), solar collectors and HTA. In parallel to P1, there is an LTA connected to a throttle valve (TV) and a hydraulic water turbine. The bottoming cycle is the ORC, which comprises a dry fluid turbine, condenser (HX2) and pump (P2).

Compared with a conventional, single-stage accumulator based DSG solar power plant, this novel system has an ORC, an HX1, a hydraulic turbine, an LTA and more solar collectors for a larger storage capacity. The additional devices are marked in blue. Thermodynamic states are marked by circles with corresponding numbers.

The system can operate in many modes due to the independent power cycles and accumulators. A few basic cases are shown in line with solar radiation in Fig.5. The 
flow diagrams of the modes are depicted in red in Fig.6.

Mode 1: Sole heat collection. V4 is open and P3 runs. The unmentioned valves or pumps are closed or off-work, as in the following cases. Water normally accumulates in the LTA before the system begins to charge and produce electricity on a sunny day. Water is pumped into the solar field and then arrives at the HTA under low radiation in the morning. The control objective in this mode is stable saturated liquid at the design temperature (e.g., $268^{\circ} \mathrm{C}$ ). The mass flow rate through $\mathrm{P} 3$ rises with the increment in the radiation.

Mode 2: Heat collection and power conversion. The system works mostly in this mode when solar radiation is available. V1, V2, V3 and V4 are open, while P1, P2 and $\mathrm{P} 3$ run. $\mathrm{P} 4$ can run if controlling the dryness fraction at the solar field outlet is necessary. Water is heated and partially vaporized by solar collectors. Saturated steam goes into the topping turbine, thereby generating power during expansion. The exhaust is condensed to saturated liquid in HX1, and is pressurized before sent back by P1. The condensation heat is used to evaporate the working fluid in the ORC. Meanwhile, water in the LTA is pumped to the HTA and heated up through the solar collectors. The mass in the LTA gradually decreases. Water leaving the solar field is in the binary phase state under nominal conditions. However, it can either be in a liquid or vapor state when the solar radiation fluctuates. Depending on the radiation, the flow rate through P3 can be altered to guarantee a constant temperature in the HTA (e.g., $268^{\circ} \mathrm{C}$ ) and steady power conversion of the RC-ORC. The total electricity generation is $\dot{w}_{R C}+\dot{w}_{O R C}$.

A possible control strategy in this mode can be briefly described, based on the 
assumption that the heat input to the RC-ORC in the nominal operating condition is $Q_{\text {rated }}$ and the solar field produces such heat at $I_{D N}=400 \mathrm{~W} / \mathrm{m}^{2}$.

(1) When $I_{D N}=400 \mathrm{~W} / \mathrm{m}^{2}$, the mass flow rate through P3 $\left(\dot{m}_{p 3}\right)$ is 0 . The mass flow rate of $\mathrm{P} 4\left(\dot{m}_{p 4}\right)$ is controlled to achieve the optimum steam outlet dryness. A fraction of $60 \%-80 \%$ has been recommended [36], which is sufficiently high to avoid an excessively large pumping power, and sufficiently low to ensure a safety margin from tube dry-out [37]. The HTA temperature remains constant because the heat collection $(Q)$ is equal to $Q_{\text {rated }}$.

(2) When $I_{D N}<400 W / m^{2}, \dot{m}_{p 3}=0 . \dot{m}_{p 4}$ is controllable. The HTA temperature gradually decreases because $Q<Q_{\text {rated }}$.

(3) When $I_{D N}>400 \mathrm{~W} / \mathrm{m}^{2}, \dot{m}_{p 3}$ is adjusted to fulfill $\dot{m}_{p 3}\left(h_{\text {out }}-h_{\text {in }}\right)=Q-$ $Q_{\text {rated }} \cdot h_{\text {out }}$ is the specific saturated liquid enthalpy of water at the nominal temperature in the HTA. The HTA temperature remains constant and the total water mass increases.

Mode 3: The first step heat discharge. When solar radiation is extremely weak or unavailable, the heat stored in the HTA will be released. V1, V2, V3 and V5 are open, while P1 and P2 run. Water in the HTA is vaporized to drive the RC-ORC. The HTA temperature drops. The system can discharge at variable pressure as in the Planta Solar 10. The LTA is not involved. The total electricity generation is $\dot{w}_{R C}+\dot{w}_{O R C}$.

Mode 4: The second step heat discharge. V6 and V7 (or V8) are open, while P2 runs. Water in the HTA is moved into the LTA through a throttle valve or a hydraulic turbine and the heat is used only to drive the ORC. The total electricity generation is $\dot{w}_{O R C}$. 
The system has a few clear advantages over those traditionally used, including the following:

(1) The storage capacity is remarkably increased. The temperature drop of water in a single accumulator during heat discharge is limited to approximately $30{ }^{\circ} \mathrm{C}$ to prevent serious performance degradation of turbines in the off-design condition. In the presence of two-stage accumulators, water in the HTA can be transferred to the LTA with a temperature differential exceeding $150{ }^{\circ} \mathrm{C}$. Significantly elevating the storage capacity is possible.

(2) The highly inefficient off-design operation of the RC and ORC can be avoided. The temperature drop of HTA in the first step heat discharge can be small (e.g., $<20{ }^{\circ} \mathrm{C}$ ) because the storage capacity no longer relies solely on the HTA, enabling high efficiency of turbines.

(3) The two-step heat discharge is unique and the power conversion is flexible. Electricity can be produced by either RC-ORC $\left(\dot{w}_{R C}+\dot{w}_{O R C}\right)$ or ORC $\left(\dot{w}_{O R C}\right)$. It is worth noting that the resilient power generation is advantageous, particularly because the consumers' demand for electricity is variable, normally high during the day and low at night. 


\section{Mathematical models}

\subsection{Thermodynamics}

\subsubsection{Solar collectors}

The heat collection in the solar field is comparatively simulated by the following two pieces of software, the System Advisor Model (SAM) created by the National Renewable Energy Laboratory [38] and Greenius developed at the Institute of Solar Research of the German Aerospace Center [39].

\subsubsection{Parameter setting in SAM}

To date, SAM has utilized the commercial, well-established software package TRNSYS tool for modeling CSP systems [40]. The overall efficiency of solar collectors $\left(\eta_{\text {col }}\right)$ is defined as the optical efficiency $\left(\eta_{\text {opt }}\right)$ minus an efficiency penalty term $\left(\eta_{\text {loss }}\right)$ representing heat losses [41]:

$$
\eta_{c o l}=\eta_{o p t}-\eta_{\text {loss }}=K \eta_{o p t, 0}-\frac{L q_{\text {loss }, a v}}{A_{c o l} I_{D N}}
$$

where $K$ is the factor which expresses the dependency of $\eta_{o p t}$ on the incidence angle of the solar radiation; $\eta_{o p t, 0}$ is the peak optical efficiency when the incidence angle is zero; $L$ is the length of receivers $(\mathrm{m}) ; q_{l o s s, a v}$ is average heat loss from receivers $(\mathrm{W} / \mathrm{m}) ; A_{c o l}$ is the aperture area of the solar collectors $\left(\mathrm{m}^{2}\right) ; I_{D N}$ is the direct normal solar irradiance $\left(\mathrm{W} / \mathrm{m}^{2}\right)$.

For the evacuated tube receivers, $q_{\text {loss,av }}$ is calculated by

$$
q_{\text {loss }, a v}=a_{0}+a_{5} \sqrt{v_{w}}+\left(a_{1}+a_{6} \sqrt{v_{w}}\right) \frac{T_{\text {in }}+T_{\text {out }}-T_{a}}{2}
$$




$$
+\left(a_{2}+a_{4} I_{D N} K\right) \frac{T_{\text {in }}^{2}+T_{\text {in }} T_{\text {out }}+T_{\text {out }}^{2}}{3}+a_{3} \frac{\left(T_{\text {in }}^{2}+T_{\text {out }}^{2}\right)\left(T_{\text {in }}+T_{\text {out }}\right)}{4}
$$

where $a_{0} \ldots a_{6}$ are the heat loss coefficients; $v_{w}$ is the wind speed $(\mathrm{m} / \mathrm{s}) ; T_{\text {in }}$ and $T_{\text {out }}$ are the solar field inlet and out temperature $\left({ }^{\circ} \mathrm{C}\right) ; T_{a}$ is the ambient temperature $\left({ }^{\circ} \mathrm{C}\right)$.

The specific parameters and their default values of PTCs and LFCs used for heat collection in SAM are listed in Table 3.

For PTCs, the factor $K$ is determined by

$$
K_{P T C}=I A M_{P T C} \cos \theta=\min \left(1, \frac{c_{0} \cos \theta+c_{1} \theta+c_{2} \theta^{2}}{\cos \theta}\right) \cos \theta
$$

where $I A M_{P T C}$ denotes the incidence angle modifier; $\theta$ is the incidence angle $\left(^{\circ}\right)$ and $c_{0}, c_{1}, c_{2}$ are the incidence angle coefficients.

For LFCs, the factor $K$ is expressed by

$$
\begin{gathered}
K_{L F C}=K_{\text {long }} K_{\text {trans }} \\
K_{\text {long }}=c_{0, \text { long }}+c_{1, \text { long }} \theta_{\text {long }}+c_{2, \text { long }} \theta_{\text {long }}^{2}+c_{3, \text { long }} \theta_{\text {long }}^{3}+c_{4, \text { long }} \theta_{\text {long }}^{4} \\
K_{\text {trans }}=c_{0, \text { trans }}+c_{1, \text { trans }} \theta_{\text {trans }}+c_{2, \text { trans }} \theta_{\text {trans }}^{2}+c_{3, \text { trans }} \theta_{\text {trans }}^{3}+c_{4, \text { trans }} \theta_{\text {trans }}^{4}
\end{gathered}
$$

where $\theta_{\text {long }}$ and $\theta_{\text {trans }}$ are the longitudinal and transverse angles $\left(^{\circ}\right.$ ); $c_{0, \text { long }} \ldots c_{4, \text { long }}$ and $c_{0, \text { trans }} \ldots c_{4, \text { trans }}$ are the incidence angle coefficients. The default values are listed in Table 4.

\subsubsection{Parameter setting in Greenius}

Greenius is a powerful simulation package for the calculation and analysis of renewable power projects. In this software, the solar collector efficiency is calculated by [42] 


$$
\begin{gathered}
\eta_{\text {col }}=K \eta_{\text {opt }, 0} \eta_{\text {cleanliness }}-\left(K a_{0} \Delta T+\frac{a_{1} \Delta T+a_{2} \Delta T^{2}+a_{3} \Delta T^{3}+a_{4} \Delta T^{4}}{I_{D N}}\right) \\
\Delta T=\frac{T_{\text {in }}+T_{\text {out }}}{2}-T_{a}
\end{gathered}
$$

where $\eta_{\text {cleanliness }}$ is the mirror cleanliness factor, which is not included in $\eta_{o p t, 0}$.

The specific parameters and their default values of PTCs and LFCs in Greenius are shown in Table 5.

For PTCs, the factor $K$ is determined by

$$
K_{P T C}=I A M_{P T C} \cos \theta=\cos \theta-\left(c_{1} \theta+c_{2} \theta^{2}+c_{3} \theta^{3}\right)
$$

The values of $c_{1}, c_{2}, c_{3}$ are $0.000525,2.86 \mathrm{e}-5$ and 0 .

For LFCs, the factor $K$ is also determined by Eq.(4), but $K_{\text {long }}$ and $K_{\text {trans }}$ are derived from Table 6 through interpolation.

\subsubsection{Calculation of the incidence angle}

When the PTC is north-south oriented and has east-west tracking, the incidence angle is calculated by [43]

$$
\cos \theta=\sqrt{1-\cos ^{2} \alpha_{s} \cos ^{2} \gamma_{s}}
$$

where $\alpha_{s}$ is the solar altitude angle $\left(^{\circ}\right) ; \gamma_{s}$ is the solar azimuth angle $\left(^{\circ}\right)$.

When the LFC is north-south oriented and has east-west tracking, the longitudinal and transverse angles are calculated by [44]

$$
\begin{gathered}
\cos \theta_{\text {long }}=\sqrt{1-\cos ^{2} \alpha_{s} \cos ^{2} \gamma_{s}} \\
\tan \theta_{\text {trans }}=\sin \gamma_{s} / \tan \alpha_{s}
\end{gathered}
$$

For horizontal PTCs and LFCs, $\alpha_{s}$ and $\gamma_{s}$ are determined by the following equations [45] 


$$
\begin{gathered}
\sin \alpha_{s}=\sin \phi \sin \delta+\cos \phi \cos \delta \cos \omega \\
\cos \gamma_{s}=\left(\sin \alpha_{s} \sin \phi-\sin \delta\right) /\left(\cos \alpha_{s} \cos \phi\right)
\end{gathered}
$$

where $\phi$ is the geographic latitude $\left(^{\circ}\right),-90^{\circ} \leq \phi \leq 90^{\circ} ; \delta$ is the solar declination $\left({ }^{\circ}\right),-23.45^{\circ} \leq \delta \leq 23.45^{\circ} ; \omega$ is the solar hour angle $\left(^{\circ}\right)$.

$\delta$ is expressed by

$$
\delta=23.45 \sin \left(360 \frac{284+n}{365}\right)
$$

where $\mathrm{n}$ represents the $\mathrm{n}^{\text {th }}$ day in a year, $1 \leq \mathrm{n} \leq 365$.

$\omega$ is calculated by

$$
\omega=0.25(A S T-720)
$$

where $A S T$ is the apparent solar time (min).

$A S T$ is expressed by

$$
A S T=L S T+E T-4(S L-L L)
$$

where $L S T$ is the local standard time (min); ET is the equation of time (min); $S L$ is the standard meridian for the local time zone $\left({ }^{\circ}\right) ; L L$ is the local longitude $\left(^{\circ}\right),-180^{\circ} \leq$ $L L \leq 180^{\circ}$.

$E T$ is calculated by

$$
\begin{gathered}
E T=9.87 \sin 2 B-7.53 \cos B-1.5 \sin B \\
B=360(n-81) / 365
\end{gathered}
$$

\subsubsection{Turbines}

The work generated by the steam turbine and ORC turbine is defined as

$$
\dot{w}_{S T}=\dot{m}_{R C}\left(h_{1}-h_{2}\right)=\dot{m}_{R C}\left(h_{1}-h_{2 s}\right) \varepsilon_{S T}
$$




$$
\dot{w}_{O T}=\dot{m}_{O R C}\left(h_{10}-h_{11}\right)=\dot{m}_{O R C}\left(h_{10}-h_{11 s}\right) \varepsilon_{O T}
$$

where $\varepsilon_{S T}$ and $\varepsilon_{O T}$ are the isentropic efficiencies of steam turbine and ORC turbine, respectively.

Regarding the off-design behavior of the turbines, the ellipse law provides a method for calculating the turbine flow rate [46]

$$
\dot{m} \frac{\sqrt{T_{1}}}{p_{1}}=k \sqrt{1-\left(\frac{p_{2}}{p_{1}}\right)^{2}}
$$

where $k$ is a constant. $\dot{m}$ is the off-design flow rate. $T_{1}$ and $p_{1}$ are the inlet temperature and pressure. $p_{2}$ is the outlet pressure. The ellipse law has been used for many years to model the off-design behavior of steam turbines.

The ratio of the off-design mass flow rate to the design can then be expressed by [47]

$$
\frac{\dot{m}}{\dot{m}_{0}}=\sqrt{\frac{T_{0}}{T_{1}}} \sqrt{\frac{p_{1}^{2}-p_{2}^{2}}{p_{01}^{2}-p_{02}^{2}}}
$$

where $\dot{m}_{0}, T_{0}, p_{01}$, and $p_{02}$ are the design flow rate, inlet temperature, inlet and outlet pressure. It is a simplified mathematic expression of the ellipse law.

\subsubsection{Heat exchanger}

The heat balance in HX1 under the nominal working conditions is expressed by

$$
\dot{m}_{R C}\left(h_{2}-h_{3}\right)=\dot{m}_{O R C}\left(h_{10}-h_{13}\right)
$$

The heat balance in HX1 in the second step of heat discharge is expressed by

$$
\dot{m}_{R C, 2 n d}\left(h_{5}-h_{6}\right)=\dot{m}_{O R C}\left(h_{10}-h_{13}\right)
$$

\subsubsection{Pumps}

The work required by $\mathrm{P} 1$ and $\mathrm{P} 2$ in the $\mathrm{RC}-\mathrm{ORC}$ is calculated by 


$$
\begin{gathered}
\dot{w}_{P 1}=\dot{m}_{R C}\left(h_{4}-h_{3}\right)=\dot{m}_{R C}\left(h_{4 s}-h_{3}\right) / \varepsilon_{P} \\
\dot{w}_{P 2}=\dot{m}_{O R C}\left(h_{13}-h_{12}\right)=\dot{m}_{O R C}\left(h_{13 s}-h_{12}\right) / \varepsilon_{P}
\end{gathered}
$$

where $\varepsilon_{P}$ is the pump isentropic efficiency.

In the second step heat discharge, water flows from the HTA to the LTA and the heat is used to drive the ORC. Pumping back the water into the HTA is necessary for further circulation. The pump power is calculated by

$$
\dot{w}_{P 3}=\dot{m}_{R C, 2 n d}\left(h_{9}-h_{8}\right)=\dot{m}_{R C, 2 n d}\left(h_{9 S}-h_{8}\right) / \varepsilon_{P}
$$

where $\dot{m}_{R C, 2 n d}$ is the water flow rate through HX1.

\subsubsection{Thermal efficiency}

\subsubsection{Thermal efficiency under nominal working conditions}

The RC, ORC and RC-ORC efficiencies are defined by

$$
\begin{gathered}
\eta_{R C}=\frac{\dot{w}_{R C}}{\dot{m}_{R C}\left(h_{1}-h_{4}\right)}=\frac{\dot{w}_{S T} \varepsilon_{g}-\dot{w}_{P 1}}{\dot{m}_{R C}\left(h_{1}-h_{4}\right)} \\
\eta_{O R C}=\frac{\dot{w}_{O R C}}{\dot{m}_{O R C}\left(h_{10}-h_{13}\right)}=\frac{\dot{w}_{O T} \varepsilon_{g}-\dot{w}_{P 2}}{\dot{m}_{O R C}\left(h_{10}-h_{13}\right)} \\
\eta_{R C-O R C}=\frac{\dot{w}_{n e t}}{\dot{m}_{R C}\left(h_{1}-h_{4}\right)}=\frac{\dot{w}_{R C}+\dot{w}_{O R C}}{\dot{m}_{R C}\left(h_{1}-h_{4}\right)}
\end{gathered}
$$

where $\varepsilon_{g}$ is the generator efficiency and $\dot{w}_{n e t}$ is the net power output.

The thermal efficiency $\left(\eta_{T}\right)$ of the DSG solar thermal power system under the nominal working conditions is expressed by

$$
\eta_{T}=\eta_{R C-O R C} \eta_{c o l}=\frac{\dot{w}_{n e t}}{I_{D N} A_{c o l}}
$$

\subsubsection{Thermal efficiency in the second step heat discharge}

The net power output by the ORC in the second step heat discharge is calculated by

$$
\dot{w}_{O R C, 2 n d}=\dot{w}_{O T} \varepsilon_{g}-\dot{w}_{P 2}-\dot{w}_{P 3}
$$


The ORC efficiency in the second step heat discharge is then expressed by

$$
\eta_{O R C, 2 n d}=\frac{\dot{m}_{O R C}\left(h_{10}-h_{11 s}\right) \varepsilon_{O T} \varepsilon_{g}-\dot{m}_{O R C}\left(h_{13 s}-h_{12}\right) / \varepsilon_{P}-\dot{m}_{R C, 2 n d}\left(h_{9 S}-h_{8}\right) / \varepsilon_{P}}{\dot{m}_{O R C}\left(h_{10}-h_{13}\right)}
$$

The equivalent solar electricity efficiency $\eta_{T, 2 n d}$ is defined by

$$
\eta_{T, 2 n d}=\eta_{O R C, 2 n d} \eta_{c o l}
$$

Since water is throttled via the TV, the power loss is defined by

$$
\dot{w}_{\text {loss }}=\dot{m}_{R C, 2 n d}\left(h_{6}-h_{7 s}\right)
$$

\subsection{Cost and payback period}

An evaluation of the cost and payback time of the entire system is not conducted due to its complexity. Instead, this work focuses on the economic aspects associated with the second step heat discharge. Compared with the traditional DGS technology, the proposed approach can facilitate a second step heat discharge (i.e., Mode 4), thereby facilitating generation of additional power per year. An equivalent payback period (EPP) with respect to the second step heat discharge is defined as

$$
E P P=\frac{C_{a d d}}{Y_{2 n d}}
$$

where $C_{a d d}$ is the additional investment associated with the novel approach, and $Y_{2 n d}$ is the annual yield via the second step heat discharge.

As shown in Fig.4, the proposed approach utilizes an ORC turbine, an internal heat exchanger (HX1), a hydraulic turbine, an LTA and additional solar collectors. The size and cost of the HX1 will be analyzed in Section 4.3.3, and it may be cheaper than a reheater in the conventional system. The energy of high pressure water from the HTA can be recovered by a hydraulic turbine, as an alternative to the throttle valve. The 
hydraulic turbine has not been used in the existing solar power systems. Accurately calculating the recovered power is difficult. In this work, the high pressure water is throttled and the cost of the hydraulic turbine is not estimated.

In the commercial DGS systems, the exhaust from the HP steam turbine is reheated and then flows into the LP steam turbine. The LP turbine and the reheater are now eliminated due to the bottoming ORC. At present ORC manufacturers like Ormat and Turboden normally provide the client with a whole module or project rather than a turbine, so it is difficult to acquire information about the cost of a single turbine. Nevertheless, the financial investment in the ORC turbine may not be greater than that in the LP steam turbine on account of the following aspects:

(1) The estimated cost of an ORC module consisting of turbine, evaporator, condenser, pump and generator in the large geothermal power system (>10 MW) is usually less than $1100 \$ / \mathrm{kW}$ [48]. The turbine cost represents a percentage from about $28 \%$ to $44.5 \%$ [49]. A turbine cost of about 308 489 $\$ / \mathrm{kW}$ can be deduced. Meanwhile, the cost of a MW scale steam turbine but not necessarily a wet steam turbine is around 0.4 million USD (400 \$/kW) [50]. The ORC and steam turbines are comparable in cost.

(2) The turbine cost is determined by the number of stages and the last stage size parameter with the power as scaling factors [51]. So far, the formulas used primarily for approximating gas/steam turbine cost have been adopted in the ORC application [52-53]. The working fluid seems to have much less impact than the power capacity on the turbine cost.

(3) A steam turbine generally requires expensive maintenance and has major overhauls 
at 5-year intervals, and the situation will be even worse for a wet steam turbine. The ORC turbine uses a dry organic fluid and is free of droplets during expansion. It has a lesser technical requirement than the wet steam turbine. The absence of condensation lowers the risk of corrosion on the turbine blades. ORC turbines can have a lifetime of about 30 years instead of 15-20 years for steam turbines [54-55], and can offer minimal maintenance cost without major overhauls [56].

In view of the preceding factors mentioned, the increase in the system capital cost is mainly attributed to the additional solar collectors and LTA. Determining the EPP is reasonable by

$$
E P P=\frac{C_{L T A}+C_{c o l, 2 n d}}{Y_{2 n d}}
$$

$C_{L T A}$ and $C_{c o l, 2 n d}$ are explained below.

\subsubsection{Cost of the LTA $\left(\boldsymbol{C}_{\boldsymbol{L T A}}\right)$}

The material cost of an accumulator is determined by

$$
C_{\text {steel }}=P_{\text {steel }} M_{\text {steel }}=P_{\text {steel }} \rho_{\text {steel }} V_{\text {steel }}
$$

where $P_{\text {steel }}$ is the price per kilogram of steel.

The total volume of steel $\left(V_{\text {steel }}\right)$ is a function of the thickness $(\delta)$, diameter $\left(D_{i}\right)$ and height $(H)$ of the accumulator. The design thickness of the cylinder accumulator and the design pressure are directly correlated [57]

$$
\delta_{c y}=\frac{p D_{i}}{2[\sigma]^{t} \phi-p}
$$

where $[\sigma]^{t}$ is permissible stress, which is regulated by the technical standard [58]; $\phi$ is the welding coefficient. The units of $p$ and $D_{i}$ are MPa and mm; 
The cylinder accumulator generally has two elliptical heads at the top and bottom. The standard ratio of the half long axis to the half short axis of an ellipse is $2: 1$. The design thickness is expressed by

$$
\delta_{\text {head }}=\frac{p}{2[\sigma]^{t} \phi-0.5 p}
$$

Corrosion allowance is considered which leads to higher cylinder and head thicknesses than those by Eq. (40) and (41), respectively.

Considering the manufacturing costs, the cost of the LTA is approximately twice as much as $C_{\text {steel }}$.

$$
C_{\text {LTA }}=2 C_{\text {steel }}
$$

\subsubsection{Cost of the additional collectors $\left(\boldsymbol{C}_{\boldsymbol{c o l}, 2 n d}\right)$}

The storage capacity of the solar system is promoted via a second step heat discharge. Meanwhile, additional solar collectors are installed to harness solar energy. The total heat released from the HTA to the LTA in the second step heat discharge is expressed by

$$
Q_{2 n d}=M_{w}\left(h_{5}-h_{6}\right)
$$

where $M_{w}$ is the total water in the mass transfer process, which is assumed to be the product of water density and HTA volume.

The additional solar collectors for $Q_{2 n d}$ is calculated by

$$
A_{c o l, 2 n d}=\frac{Q_{2 n d}}{t_{s, r e f} I_{D N, r e f} \eta_{c o l, r e f}}
$$

where $t_{s, r e f}$ is the reference sunshine duration (h); $I_{D N, r e f}$ is the reference direct normal solar irradiance $\left(\mathrm{W} / \mathrm{m}^{2}\right)$ and $\eta_{\text {col,ref }}$ is the solar collector efficiency in the 
reference condition.

The cost of solar collectors is expressed by

$$
C_{c o l, 2 n d}=P_{c o l} A_{c o l, 2 n d}
$$

where $P_{c o l}$ is the overall collector price per square meter, including costs of manufacturing, assembly, equipment and construction activities.

\subsubsection{Annual revenues $\left(\boldsymbol{Y}_{2 n d}\right)$}

The annual electricity output is the product of annual heat gain and the ORC efficiency

$$
W_{2 n d}=\eta_{O R C, 2 n d} \sum_{1}^{8760}\left(\eta_{c o l} I_{D N} A_{c o l, 2 n d}\right)
$$

The annual yield is

$$
Y_{2 n d}=P_{e} W_{2 n d}
$$

where $P_{e}$ is the electricity price per kWh.

\section{Results and discussion}

The two-stage accumulators and Rankine cycles are expected to be applicable to common DSG systems using PTCs, LFCs and heliostats. However, only PTCs and LFCs are used as examples in the following analysis.

Benzene and pentane are selected as the ORC fluids. Theses fluids have been widely investigated [59] and both have been utilized in practical systems [60]. Particularly, pentane is a popular working fluid adopted by Ormat Technologies Inc. [61], which has built more than 1000 ORC plants of up to $1701 \mathrm{MW}$ [62]. The critical temperatures of 
benzene and pentane are $288.9{ }^{\circ} \mathrm{C}$ and $196.6{ }^{\circ} \mathrm{C}$. Subcritical cycles are considered, which offer a constant temperature and pressure in the vaporization process.

A few assumptions are made in the calculation, as shown in Table 7. In the event of a market price from China, a current exchange rate from China Renminbi (CNY) to US dollar (USD) of 0.16 is applied.

\subsection{Thermodynamic performance under design conditions}

Wet steam turbines have been used in nuclear plants for decades [68]. After significant development, modern wet turbines can handle binary phase steam at a dryness level lower than $90 \%$. With respect to their well-established development, wet steam turbines in a commercial nuclear plant, namely Qinshan Nuclear Power Plant (300 MW, China), serve as reference. A few parameters under the nominal conditions are listed in Table 8 [69]. The HP and LP turbines have an isentropic efficiency of approximately $78 \%$. The temperature and pressure are close to those in the Puerto Errado 1 and Puerto Errado 2 plants as shown in Table 1.

In this simulation, the wet steam turbine in the topping cycle has the same design temperature and pressure (inlet and outlet) as the HP turbine in Qinshan Nuclear Power Plant. However, a turbine efficiency of $75 \%$ is adopted due to the lower power capacity (about $5 \mathrm{MW}$ ). The design parameters in the bottoming cycle are listed in Table 9. Water is not an organic fluid, but is considered alongside benzene and pentane to examine its applicability. In the case of water, Point 10 is the outlet of the HX1. An additional superheater (SH), which is not included in Fig.4, is required in order to guarantee a high 
quality of steam during expansion and the heat is supplied by the HTA.

The cycle efficiency, mass flow rate, power output and heat input are displayed in Table 10. The total electricity output is $10 \mathrm{MW}$. The ORC efficiency $\left(\eta_{\text {ORC }}\right)$ is approximately $62 \%-67 \%$ of the overall thermal efficiency $\left(\eta_{R C-O R C}\right) . \eta_{R C-O R C}$ for the organic fluids varies from $25.3 \%$ to $27.6 \%$. Compared with the organic fluids, water absorbs heat in the superheater from 161.3 to $217.6^{\circ} \mathrm{C}$. The heat is directly transferred from the HTA, thereby leading to significant exergy destruction. Water offers a higher thermal efficiency $(27.8 \%)$ than benzene, but the relative increment is insignificant because the bottoming wet steam turbine has an efficiency of $75 \%$, which is similar to the LP turbine efficiency in the nuclear plants and is lower than the ORC turbine efficiency (i.e., $82 \%)$.

The output of the ORC $\left(\dot{w}_{O R C}\right)$ is greater than the $\mathrm{RC}\left(\dot{w}_{R C}\right)$ and the ratio ranges from 1.13 to 1.42 . The heat input from the solar collectors that is, $\dot{m}_{R C}\left(h_{1}-h_{4}\right)$ is in inverse proportion to $\eta_{R C-O R C}$. The mass flow rate of ORC ( $\left.\dot{m}_{O R C}\right)$ and RC $\left(\dot{m}_{R C}\right)$ varies with the organic fluid.

Notably, the design parameters originating from the nuclear plants maximize the reliability. However, these parameters might not be optimum from the viewpoint of thermodynamics. Given the hot and cold side temperature of the RC-ORC, $\eta_{R C}$ decreases with the increment of the ORC evaporation temperature $\left(T_{10}\right) \cdot \eta_{R C-O R C}$ is not a monotonic increasing function of $T_{10}$ due to the trade-off between $\eta_{R C}$ and $\eta_{O R C}$, In general, $\eta_{R C-O R C}$ initially increases when $T_{10}$ rises from the environment temperature, and reaches a maximum value. It then decreases with a further increase of 
$T_{10}$. With the hot side temperature of $268.2^{\circ} \mathrm{C}$ the optimum design $T_{10}$ can possibly exceed $161.3{ }^{\circ} \mathrm{C}$, especially in the presence of benzene [70]. A high $T_{10}$ in design is beneficial because the pressure ratio for the wet steam turbine is decreased and the quality of the exhaust is improved. The technical challenges associated with wet steam turbines are reduced, thereby resulting in high turbine efficiency. Moreover, high power efficiency in the second step heat discharge is possible.

Though heat transfer irreversibility is evident in the HX1, the RC-ORC may have a higher efficiency than a sole RC at given hot and cold side temperatures. For the latter, the pressure loss through a reheater can be significant. It is approximately $64 \mathrm{kPa}$ in Qinshan Nuclear Power Plant, and should be greater in the DSG systems with a lower power capacity and heat source temperature. Steam pressure drops in the HX1 in practice, but the drop is less significant because of the condensation process and does not affect the power output of the steam turbine, as shown in Section 4.3.3. Instead, it leads to a lower intake pressure of the pump (P1), and a higher pump power that is generally less than the turbine output by two orders of magnitude.

\subsection{Thermodynamic performance in the second step heat discharge}

In the first step heat discharge, water is vaporized in the HTA and circulated in the RC. Similar to a typical single-stage accumulator, temperature and pressure drop in the HTA while the total mass is nearly constant. The first step heat discharge is conventional and does not contribute to the benefits of the proposed approach. Therefore the thermodynamic performance in this step is not investigated. 
The second step heat discharge is assumed to begin with an HTA temperature of $240{ }^{\circ} \mathrm{C}$ due to the following reasons. As the HTA temperature drops from $268.2{ }^{\circ} \mathrm{C}$ to $240{ }^{\circ} \mathrm{C}$, the saturation pressure of water falls from approximately 5.3 to $3.3 \mathrm{MPa}$. According to the Flügel formula in Eq.(22), the mass flow rate will decrease to approximately $60 \%$ of the rated value. The relative decrement in the turbine efficiency will be approximately $20 \%$ [71]. Given a backpressure of $0.817 \mathrm{MPa}$ at $171.3{ }^{\circ} \mathrm{C}$, the isentropic enthalpy drop at an inlet temperature of $268.2^{\circ} \mathrm{C}$ is $338.0 \mathrm{~kJ} / \mathrm{kg}$. It becomes $261.4 \mathrm{~kJ} / \mathrm{kg}$ at $240{ }^{\circ} \mathrm{C}$, and the relative decrement is $22.7 \%$. It can be deduced that the thermal efficiency of the topping RC will fall to approximately $60 \%$ of the design value. The ORC efficiency is affected correspondingly by the reduced RC load. Consequently, the thermal efficiency of the RC-ORC at a temperature lower than $240{ }^{\circ} \mathrm{C}$ may be less than the ORC nominal efficiency as listed in Table 10.

The T-Q diagrams in the second step heat discharge are depicted in Fig.7, which usefully reveal the relationship between fluid temperature and heat transfer rate in the HX1. As a hot side fluid, water leaves the HTA at a constant temperature but reaches the LTA inlet at different temperatures. The heat transfer is related to the characteristics of the bottoming fluids. For benzene and water, the minimum temperature difference ( $\Delta T_{\min }=10^{\circ} \mathrm{C}$ ) occurs at the saturated liquid state (i.e., pinch point). For pentane, $\Delta T_{\min }$ takes place at its inlet.

Benzene and water are accompanied by a high LTA inlet temperature attributed to the large latent heat of vaporization. The ratio of specific latent heat of water and benzene in the evaporation process to the total energy in the heating process (i.e., $h_{10}-$ 
$\left.h_{13}\right)$ is $79.6 \%$ and $58.2 \%$, respectively, while it is $36.5 \%$ for pentane. Most of the heat is used for vaporization in the case of water and benzene, thereby resulting in the high average temperature of the hot side fluid.

The thermodynamic performance correlated with the heat transfer in Fig.7 is listed in Table 11. The bottoming cycle can work in nominal conditions for each fluid. $\dot{m}_{R C, 2 n d}$ may be different from nominal values because the hot side water in the second step heat discharge process is only heat transfer media rather than expander fluid. A total of 9 to 13 hours of cycle operation $\left(t_{O R C}\right)$ are necessary for the organic fluids to complete the second step heat discharge process, which is evidently longer than that for water.

Given the volume of the accumulators, the total power that can be generated in the second step heat discharge $\left(W_{2 n d}\right)$ is defined by the product of the heat transfer in the HTA and the cycle efficiency $\left(\eta_{O R C, 2 n d}\right) . \eta_{O R C, 2 n d}$ is calculated by Eq.(34). The discharge and the pumping process of water from the LTA to the HTA might not proceed simultaneously, but the pump power $\left(\dot{w}_{p 3}\right)$ must be included in the $\eta_{O R C, 2 n d}$ for a circulation loop. $\dot{w}_{p 3}$ ranges from 297.4 to $579.8 \mathrm{~kW}$. More pump power is demanded when the bottoming fluids are water and benzene due to the relatively large flow rate through P3. $\dot{w}_{p 3}$ is approximately equal to $5.4 \%$ of the nominal ORC output in the case of pentane. The power loss $\left(\dot{w}_{\text {loss }}\right)$ in the throttling process varies from 139 to $254 \mathrm{~kW}$. $\dot{w}_{\text {loss }}$ is significantly lower than $\dot{w}_{p 3}$ owing to the pumping irreversibility and the pressure difference between Points 9 and $6\left(p_{9}>p_{6}\right)$. The parameter distribution of the topping water in the second step heat discharge is shown in Table 12. Vaporization in 
the throttling process occurs but the vapor fraction is only about $0.1 \%$. A preheater can be placed between the throttle valve and LTA to address the vapor if necessary.

$W_{2 n d}$ ranges from 35.6 to $67.3 \mathrm{MWh}$. Assuming an average efficiency of $80 \%$ of the nominal value during the first step heat discharge, $W_{1 s t}$ is estimated to be 16.0, 14.6 and 16.4 MWh for benzene, pentane and water, respectively, with a temperature drop from 268.2 to $240{ }^{\circ} \mathrm{C}$. Therefore, $W_{2 n d} / W_{1 s t}$ is $3.1,4.6$ and 2.2. The second step heat discharge can increase the system storage capacity by $460 \%$.

Benzene offers a higher nominal ORC efficiency than pentane, but it does not guarantee greater $W_{2 n d}$, due to the higher temperature at Point 6. $W_{2 n d}$ using pentane is approximately 1.9 times that using water. Water does not seem to be an attractive bottoming cycle fluid and will not be considered in the following discussion due to a considerably smaller storage capacity and the additional superheater requirement.

Variation of the hot side water temperature at the HX1 outlet $\left(\mathrm{T}_{6}\right)$ with the minimum temperature difference $\Delta T_{\min }$ at a given $T_{5}$ of $240{ }^{\circ} \mathrm{C}$ is displayed in Fig.8. Water outlet temperature has the same increment as $\Delta T_{\min }$ when the bottoming fluid is pentane, because $\Delta T_{\min }$ occurs at the HX1 outlet. The water outlet temperature in the presence of benzene is also correlated to $\Delta T_{\min }$, but it increases at a faster rate.

\subsection{Cost regarding the use of the second step heat discharge}

\subsubsection{Cost of additional solar collectors}

The second step heat discharge increases the system storage capacity, but additional solar collectors must be used to harness solar energy during the day. The reference direct 
normal solar irradiance $\left(I_{D N, r e f}\right)$ is $800 \mathrm{~W} / \mathrm{m}^{2}$, and is perpendicular to the collector aperture. The reference wind speed $\left(v_{w, r e f}\right)$ is $5 \mathrm{~m} / \mathrm{s}$. The PTC efficiency $\left(\eta_{P T C}\right)$ and LFC efficiency $\left(\eta_{L F C}\right)$ are displayed in Table 13. In the same situation, the efficiency calculated by SAM is higher than that by Greenius. The additional aperture area $\left(A_{c o l, 2 n d}\right)$ of the solar collectors determined by Eq.(44) is shown in Table 14. The reference sunshine duration $\left(t_{s, r e f}\right)$ is $8.37,6.89,6.39,5.53,7.65$ and $4.73 \mathrm{~h}$ for Phoenix, Sacramento, Cape Town, Canberra, Lhasa and Delingha, respectively, based on the typical weather data [72]. $A_{c o l, 2 n d}$ is proportional to the total heat released in the second step heat discharge. Benzene offers a lower $A_{c o l, 2 n d}$ than pentane, which is attributed to the smaller storage capacity. $A_{c o l, 2 n d}$ is inversely proportional to $t_{s, r e f}$. The least area is used in Phoenix with the most abundant solar resource. The aperture area is approximately $19 \%$ larger than that of the PTCs for any given organic fluid and region due to the low overall efficiency of LFCs. However, the cost of the LFCs is lower than the PTCs, regardless of the larger collector area. This finding confirms the economic advantage of LFCs.

\subsubsection{Cost of the LTA}

As shown in Table 12, in the case of pentane, the LTA operates at a temperature below $100{ }^{\circ} \mathrm{C}$, thereby resulting in a low accumulator cost. The LTA for the bottoming fluid of benzene may have a higher technical requirement. 10 accumulators are placed in parallel to produce a total volume of $2500 \mathrm{~m}^{3}$. For one accumulator of $250 \mathrm{~m}^{3}$ at a design temperature of $120^{\circ} \mathrm{C}$, the recommended diameter $\left(D_{i}\right)$, wall thickness $\left(\delta_{c y}\right)$ 
and height $\left(H_{c y}\right)$ are approximately $4670 \mathrm{~mm}, 9.30 \mathrm{~mm}$ and $16.06 \mathrm{~m}$, respectively. The corresponding cost of the LTA is 24000 USD (150000 CNY) [70]. Therefore, the total cost of the LTA of $2500 \mathrm{~m}^{3}$ is 0.24 million USD.

\subsubsection{Cost of the $H X 1$}

The HX1 serves as the condenser for the topping cycle and the evaporator for the bottoming cycle. Though heat exchangers of two side fluids undergoing phase change have not been used in CSP systems, these heat exchangers have been widely used in the cascade refrigeration systems [73-74]. Commercial products are available from many manufacturers [75-76] and the HX1 is technically feasible.

Selection of the HX1 is subject to the working conditions in Modes 2 and 4. However, the HX1 determined by Mode 2 should be sufficient for the heat transfer in Mode 4. One reason for this is that $\Delta T_{\min }=10^{\circ} \mathrm{C}$ is assumed in Mode 2 for the sake of the overall cycle efficiency. In Mode 4, $\Delta T_{\min }$ can be higher as shown in Fig.8, in which case the average temperature difference between water and the organic fluids would be enlarged. It will have no influence on the ORC efficiency in the second step heat discharge, although the storage capacity is slightly decreased. Using pentane as an example, when $\Delta T_{\min }$ in Mode 4 is elevated from 10 to $20^{\circ} \mathrm{C}, W_{2 n d}$ is reduced by approximately $5 \%$, whereas the logarithmic mean temperature difference rises from approximately 16.1 to $27.1^{\circ} \mathrm{C}$. Another reason is that the velocity of water through $\mathrm{HX} 1$ driven by the pressure difference between the HTA and LTA can be high, thereby leading to a high heat transfer coefficient in Mode 4. 
HTRI software, which is considered to be the industry's most advanced thermal process design and simulation software [77], is used to estimate the heat transfer area and cost of the HX1. A U-tube heat exchanger with fluids of water/steam and pentane is exemplified, as shown in Fig.9. Pentane runs upward through the tubes and is vaporized. Water/steam flows over the tubes and is condensed. The parameters of the HX1 are listed in Table 15. The required heat transfer area is approximately $2000 \mathrm{~m}^{2}$ and the estimated cost is approximately $0.24 \sim 0.32$ million USD (1.5 2.0 million CNY).

The HX1 might not lead to a significantly higher cost than a superheater/reheater, though the latter has a smaller heat transfer rate. The heat transfer coefficient of superheated steam is significantly lower than that of saturated steam [78]. Typically, for a horizontal coil surrounded with water (similar to a reheater or superheater embedded in the HTA), the overall heat transfer coefficient might be as low as 50 to $100 \mathrm{~W} / \mathrm{m}^{2 \circ} \mathrm{C}$ if the inner fluid is superheated steam, but $1200 \mathrm{~W} / \mathrm{m}^{2 \circ} \mathrm{C}$ in the case of saturated steam [79].

The influence of HX1 on the system cost can be indirectly evaluated by considering the following points. Numerous ORC-based geothermal power plants exist worldwide with a water temperature around $100^{\circ} \mathrm{C}$ [61]. An example is the newly built Akca Enerji plant [80]. This plant has a gross electricity generation of $3.878 \mathrm{MW}$, which is driven by geothermal brine at a temperature of $105^{\circ} \mathrm{C}$. First, the difference between the ORC evaporation and condensation temperature is around $50-60{ }^{\circ} \mathrm{C}$, which is considerably less than that in this work $\left(126^{\circ} \mathrm{C}\right)$. Given the same net electricity output, the heat input of the plant should be at least twice that of an ORC system operating at $161{ }^{\circ} \mathrm{C}$. Second, 
for the sake of efficient power conversion the mean temperature difference between the geothermal fluid and ORC fluid in the evaporator of the plant should be lower than that of the HX1 in Table 15. Third, the cost of the geothermal plant is mainly due to the ORC turbine, drilling, condenser and evaporator. Drilling costs typically range from 20 to $50 \%$ of the total investment cost of a geothermal power plant [81]. Therefore, the evaporator should not play a significant role in the total cost of the geothermal plant. Similarly, the impact of the HX1 on the ORC system cost should be limited.

\subsubsection{Cost of ORC turbine}

As mentioned in Section 3.2, the ORC turbine is possibly more cost-effective than an LP steam turbine due to the higher efficiency and lower technical requirement. An additional investment on turbines is not expected.

\subsubsection{Cost of land}

Land cost is not considered due to its significant variability. For a PTC with an aperture width of $5.8 \mathrm{~m}$ and an LFC with an aperture width of $11.5 \mathrm{~m}$, the distance between neighboring rows may be 18 and $2 \mathrm{~m}$, respectively [82]. The land cost is approximately $3.1 \%$ of the total CSP system investment [83], while the cost of the solar collectors is around $40 \%$ of the total investment [84-85]. Therefore, the land cost is supposed to be less than $8.0 \%$ of the solar collectors.

\subsection{Equivalent payback period (EPP)}

The annual heat gain per square meter from the collectors is listed in Table 16 and 
the EPP is presented in Table 17. The results are first categorized by the fluids used, and then subcategorized by simulation tools and collector types. Notably, given the working fluid, region and solar collector, $E P P$ is nearly independent of the solar collector aperture area owing to the insignificant LTA cost. More solar collectors lead to linearly increased collector investment and annual electricity yield. Therefore, the ratio of investment to yield remains nearly the same. The advantages of adding the LTA is evident. The EPP is less than 5 years in areas of rich solar resource such as Phoenix, Sacramento, Cape Town, Canberra and Lhasa.

The PTCs offer a lower EPP than the LFCs. Although the initial investment in LFCs is smaller, an extended payback time might be necessary. The investment is determined at $I_{D N, \text { ref }}=800 \mathrm{~W} / \mathrm{m}^{2}$. In the yearly operation of the solar system, the incidence angle of solar radiation varies with time and season. LFCs have a higher cosine loss and lesser operation hours than those of the PTCs. Given the solar collector area, region and working fluid in Table 14, the annual solar energy received by LFCs is less than that by PTCs.

The EPP should be remarkably shorter than that of conventional DSG systems using a single-stage accumulator because the equivalent solar electricity efficiency $\left(\eta_{T, 2 n d}\right)$ in the second step heat discharge is more than half $\eta_{T, 0}$ in the nominal operation (Mode 2). For example, $\eta_{O R C, 2 n d}$ is $17.1 \%$ and $14.9 \%$ for benzene and pentane, respectively, which is approximately $59 \%-62 \%$ of the nominal RC-ORC efficiency as shown in Table 10. $\eta_{T, 2 n d}$ of $7.5 \%-8.5 \%$ can be expected while the investment is mostly in the solar collectors. For the single-stage accumulator based 
system, the proportion of the collector cost in the entire system investment should be less than 50\%. Even for a high temperature, large-scale PTC-CSP system involving a stricter technical requirement for heat collection and a proportionally lower power block cost, the cost proportion of solar collectors is below 40\% [83]. By launching a second step heat discharge, electricity can be produced at an efficiency higher than $50 \%$ of the single-stage accumulator system but the investment is less than $50 \%$. From this viewpoint, the proposed system of two-stage accumulators is more profitable than the conventional DSG systems.

The proposed system is also expected to be more economical than the conventional solar ORC systems. In the latter, irreversibility is significant in the heat transfer from the solar field HTF to the organic fluids. Though the HTF temperature can reach above $300{ }^{\circ} \mathrm{C}$, the $\mathrm{ORC}$ evaporation temperature generally ranges from $150{ }^{\circ} \mathrm{C}$ to $190{ }^{\circ} \mathrm{C}$. For example, the pentane evaporation temperature is approximately $170{ }^{\circ} \mathrm{C}$ in the Saguaro Power Plant (PTC-ORC) [86], with a pressure of $2.23 \mathrm{MPa}$ and a gross electricity efficiency of $7.5 \%$, which is close to $\eta_{T, 2 n d}$. The proposed system structurally differs from the conventional solar ORC in the steam turbine. The two kinds of systems should have similar heat collection efficiencies, but the heat quality for the former is higher because water leaves the collectors in a saturated steam state rather than a pure liquid state. For any given collector area and storage size of a solar ORC, by employing an $x$ MW steam turbine at the topping cycle the heat supplied to the ORC will be reduced by approximately $x$ MW according to the first law of thermodynamics and the ORC output will be decreased by $x \eta_{O R C}$. Therefore the net increment in the power output will 
be approximately $x\left(1-\eta_{O R C}\right)$. Given a daily steam turbine operation time of 8 hours and turbine cost of 0.4 million USD/MW [50], the annual revenue will be approximately 0.44 million USD and the payback time for the turbine will be less than one year.

Finally, a comparison between the proposed system and the mainstream CSP plants can be carried out. For the latter, thermal oil as the HTF and molten salts for storage are commonly adopted [87]. The gross electricity efficiency is around $15 \%$ at the solar field outlet temperature and pressure of $393{ }^{\circ} \mathrm{C}$ and $10 \mathrm{MPa}$, respectively. The proposed system should have a solar electricity efficiency near that of the mainstream CSP systems on a thermodynamic basis. The steam saturation temperature at $10 \mathrm{MPa}$ is approximately $311^{\circ} \mathrm{C}$. Most heat transferred to the Rankine cycle is utilized to vaporize water and the heat absorbed by water at the superheated state is significantly less. For example, given the pressure of $10 \mathrm{MPa}$, the enthalpy of steam only increases by approximately $372 \mathrm{~kJ} / \mathrm{kg}$ when the temperature rises from 311 to $400{ }^{\circ} \mathrm{C}$, which is less than $1 / 8$ of the total heat input. The improvement of $\eta_{R C}$ by a high degree of superheat is limited. The Carnot efficiency is approximately $46 \%$ at $311{ }^{\circ} \mathrm{C}$ and $42 \%$ at $260{ }^{\circ} \mathrm{C}$. The proposed system has a lower heat-to-power conversion efficiency than the mainstream CSP systems. However, it has some technical advantages that can lead to a smaller capital cost:

(1) The control strategy is relatively simple. In mainstream CSP systems, the superheater and reheater are essential and complex measures must be taken in the process of heat transfer from oil to water under fluctuating solar radiation to guarantee the safe operation of the turbine. Contrary to these CSP systems, water leaving the HTA 
in the proposed system can be either in liquid, liquid-steam mixture or saturated steam state. As shown in Fig.4, the mass flow through P3 during the day can be adjusted depending on solar irradiance. Due to heat capacity in the HTA, the inlet conditions of the steam turbine can remain constant and do not require a sophisticated control strategy.

(2) Heat collection and storage are easier. The operating temperature of solar collectors of about $270{ }^{\circ} \mathrm{C}$ is appreciably lower than that of the mainstream CSP systems $\left(400^{\circ} \mathrm{C}\right.$ or higher). Sealing failure/degradation of the receiver may be eased. The concentration ratio can also be lowered, thereby reducing the technical requirements of the tracking system. Thermal oil that requires periodical replacement is eliminated. The problems related to the low thermal conductivity and high melting point (which causes the freezing) of molten salts are overcome.

\section{Future work}

The ORC evaporation temperature could be optimized in the future by establishing mathematical models for the wet steam turbine. The thermo-economic performance of the system would be investigated by considering investments in the turbines, solar field and HTA. As an alternative to the wet steam turbine, an ORC turbine could be used in the topping cycle. This usage would entail a secondary heat transfer between the water/steam in the HTA and the organic fluid, but a higher turbine efficiency is expected with a lower technical challenge. 


\section{Conclusion}

The proposed approach has great potential to solve the storage problem inherent in the DSG technology. In principle, the two-stage accumulator system differs from existing solar thermal storage technologies. The HTA first experiences a mass-unvaried heat discharge process, and then undergoes an isothermal process. The two-stage accumulators combine the advantages of the conventional single-stage accumulator and two-tank storage system, and are a perfect match to the two-stage steam-organic Rankine cycles.

By enlarging the water temperature drop during heat discharge, the storage capacity of the system can be increased from about 14.6 MWh with a single-stage accumulator to 67.3 MWh with an additional LTA. Simultaneously, highly inefficient operation of the RC is avoided and the ORC can work stably, especially during the second step heat discharge.

Water is not an attractive fluid of the bottoming cycle owing to the large latent heat of vaporization and the superheating requirement. Compared with benzene and pentane, water has a slightly higher heat-to-power efficiency (27.8\%) under the nominal conditions but a significantly smaller storage capacity in the second step heat discharge (35.6 MWh).

A shorter EPP is achieved when using benzene due to a higher solar thermal electricity efficiency. The EPP related to the LTA and additional solar collectors is generally less than 5 years in Phoenix, Sacramento, Cape Town, Canberra and Lhasa.

The RC-ORC-driven DSG solar thermal power system of two-accumulator storage 
is an improvement on that using a single-stage accumulator. With the second step heat discharge, cost-effective storage for the DSG system becomes possible for a long time period.

\section{Acknowledgements}

Sponsored by the EU Marie Curie International Incoming Fellowships Program (703746), National Science Foundation of China (5171101721, 51776193) and Dongguan Innovative Research Team Program (2014607101008). Thanks to Rob Gordon for the helpful written English correction and stimulating discussion.

\section{References}

[1] NREL. Concentrating Solar Power Projects by Technology, http://www.nre 1.gov/csp/solarpaces/by_technology.cfm; 2018 [accessed 03 January 2018].

[2] Eck M, Steinmann W-D. Direct Steam Generation in Parabolic Troughs: First Results of the DISS Project. J Sol Energy Eng Trans-ASME 2002;124:134-9. doi:10.1115/1.1464125.

[3] Alguacil M, Prieto C, Rodriguez A, Lohr J. Direct steam generation in parabolic trough collectors. Energy Procedia 2013;49:21-9. doi:10.1016/j.egypro.2014.03.003.

[4] Leonel Reyes Ochoa. Engineering Aspects of a Parabolic Trough Collector Field with Direct Steam Generation and an Organic Rankine Cycle. Master of Science in Energy Systems Engineering, FH Aachen University of Applied Sciences, 
2014.

[5] Siemens. Steam turbines for CSP plants, http://m.energy.siemens.com/hq/p ool/hq/power-generation/steam-turbines/downloads/steam-turbine-for-csp-plant s-siemens.pdf; 2011 [accessed 01 February 2018].

[6] Steinmann WD, Eck M. Buffer storage for direct steam generation. Sol Energy 2006;80:1277-82. doi:10.1016/j.solener.2005.05.013.

[7] Pirasaci T, Goswami DY. Influence of design on performance of a latent heat storage system for a direct steam generation power plant. Appl Energy 2016;162:644-52. doi:10.1016/j.apenergy.2015.10.105.

[8] Bai FW, Xu C. Performance analysis of a two-stage thermal energy storage system using concrete and steam accumulator. Appl Therm Eng 2011;31:276471. doi:10.1016/j.applthermaleng.2011.04.049.

[9] Guédez R, Arnaudo M, Topel M, Zanino R, Hassar Z, Laumert B. Technoeconomic performance evaluation of direct steam generation solar tower plants with thermal energy storage systems based on high-temperature concrete and encapsulated phase change materials. AIP Conf Proc 2016;1734. doi:10.1063/1.4949158.

[10] Birnbaum J, Eck M, Fichtner M, Hirsch T, Lehmann D, Zimmermann G. A Direct Steam Generation Solar Power Plant With Integrated Thermal Storage. J Sol Energy Eng Trans-ASME 2010;132:31014. doi:10.1115/1.4001563.

[11] Laing D, Bahl C, Bauer T, Lehmann D, Steinmann WD. Thermal energy storage for direct steam generation. Sol Energy 2011;85:627-33. 
doi:10.1016/j.solener.2010.08.015.

[12] González-Roubaud E, Pérez-Osorio D, Prieto C. Review of commercial thermal energy storage in concentrated solar power plants: Steam vs. molten salts. Renew Sust Energ Rev 2017;80:133-48. doi:10.1016/j.rser.2017.05.084.

[13] Casati E, Galli A, Colonna P. Thermal energy storage for solar-powered organic Rankine cycle engines. Sol Energy 2013;96:205-19. doi:10.1016/j.solener.2013.07.013.

[14] Beckmann G, Gilli PV. Thermal Energy Storage. Verlag Wien: Springer; 1984.

[15] Osuna R, Olavarría R, Morillo R, Sánchez M, Cantero F, Fernández-Queroa V, Robles P, López del Cerro T, Esteban A, Cerón F, Talegón J, Romero M, Téllez F, Marcos M, Martínez D, Valverde A, Monterreal R, Pitz-Paal R, Brakmann G, Ruiz V, Silva M, Menna P. Ps10, Construction of a 11MW Solar Thermal Tower Plant in Seville, Spain. SolarPaces 2006.

[16] Power Plant. Puerto Errado 2, http://www.puertoerrado2.com/projekt/kraftw erk/; 2013 [accessed 14 February 2018].

[17] Birnbaum J, Feldhoff JF, Fichtner M, Hirsch T, Jöcker M, Pitz-Paal R, Zimmermann G. Steam temperature stability in a direct steam generation solar power plant. Sol Energy 2011;85:660-8. doi:10.1016/j.solener.2010.10.005.

[18] Guo S, Liu DY, Chen X, Chu Y, Xu C, Liu QM, Zhou L. Model and control scheme for recirculation mode direct steam generation parabolic trough solar power plants. Appl Energy 2017;202:700-14. doi:10.1016/j.apenergy.2017.05.127. 
[19] Dipippo R. Geothermal Power Plants: Principles, Applications, Case Studies and Environmental Impact. 2nd ed. Butterworth Heinemann; 2008.

[20] Turboden. Turboden ORC Technology, http://www.turboden.com/turboden-orctechnology/1065/innovation; 2018 [accessed 12 February 2018].

[21] Baumann K. Some recent developments in large steam turbine practice. J Inst Electr Eng 1921;59:565-623. doi:10.1049/jiee-1.1921.0040.

[22] Rashid MH. Electric Renewable Energy Systems. 1st ed. Academic Press; 2015.

[23] Freeman J, Hellgardt K, Markides CN. An assessment of solar-powered organic Rankine cycle systems for combined heating and power in UK domestic applications. Appl 2015;138:605-20. doi:10.1016/j.apenergy.2014.10.035.

[24] Manfrida G, Secchi R, Stańczyk K. Modelling and simulation of phase change material latent heat storages applied to a solar-powered Organic Rankine Cycle. Appl Energy 2016;179:378-88. doi:10.1016/j.apenergy.2016.06.135.

[25] Quoilin S, Orosz M, Hemond H, Lemort V. Performance and design optimization of a low-cost solar organic Rankine cycle for remote power generation. Sol Energy 2011;85:955-66. doi:10.1016/j.solener.2011.02.010.

[26] Kosmadakis G, Manolakos D, Papadakis G. Parametric theoretical study of a two-stage solar organic Rankine cycle for RO desalination. Renew Energy 2010;35:989-96. doi:10.1016/j.renene.2009.10.032.

[27] Delgado-Torres AM, García-Rodríguez L. Design recommendations for solar organic Rankine cycle (ORC)-powered reverse osmosis (RO) desalination. 
Renew Sust Energ Rev 2012;16:44-53. doi:10.1016/j.rser.2011.07.135.

[28] Li J, Li PC, Pei G, Alvi JZ, Ji J. Analysis of a novel solar electricity generation system using cascade Rankine cycle and steam screw expander. Appl Energy 2016;165:627-38. doi:10.1016/j.apenergy.2015.12.087.

[29] Li J, Li PC, Gao GT, Pei G, Su YH, Ji J. Thermodynamic and economic investigation of a screw expander-based direct steam generation solar cascade Rankine cycle system using water as thermal storage fluid. Appl Energy 2017;195:137-51. doi:10.1016/j.apenergy.2017.03.033.

[30] Turboden. Concentrated Solar Power, https://www.turboden.com/application s/1056/concentrated-solar-power; 2017 [accessed 01 November 2017].

[31] Prieto C, Rodríguez A, Patiño D, Cabeza LF. Thermal energy storage evaluation in direct steam generation solar plants. Sol Energy 2018;159:501-9. doi:10.1016/j.solener.2017.11.006.

[32] Al-Sulaiman FA. Energy and sizing analyses of parabolic trough solar collector integrated with steam and binary vapor cycles. Energy 2013;58:561-70. doi:10.1016/j.energy.2013.05.020.

[33] Al-Sulaiman FA. Exergy analysis of parabolic trough solar collectors integrated with combined steam and organic Rankine cycles. Energy Conv Manag 2014;77:441-9. doi:10.1016/j.enconman.2013.10.013.

[34] Liu B, Rivière P, Coquelet C, Gicquel R, David F. Investigation of a two stage Rankine cycle for electric power plants. Appl Energy 2012;100:285-94. doi:10.1016/j.apenergy.2012.05.044. 
[35] Angelino G, Invernizzi C, Molteni G. The potential role of organic bottoming Rankine cycles in steam power stations. Proc Inst Mech Eng Part A-J Power Energy 1999;213:75-81. doi:10.1243/0957650991537446.

[36] Hirsch T, Feldhoff JF, Hennecke K, Pitz-Paal R. Advancements in the field of direct steam generation in linear solar concentrators-a review. Heat Transf Eng 2014;35:258-71. doi:10.1080/01457632.2013.825172.

[37] Aurousseau A, Vuillerme V, Bezian JJ. Control systems for direct steam generation in linear concentrating solar power plants - A review. Renew Sust Energ Rev 2016;56:611-30. doi:10.1016/j.rser.2015.11.083.

[38] NREL. System Advisor Model, http://sam.nrel.gov/; 2017 [accessed 21 February 2018].

[39] DLR. Greenius, http://freegreenius.dlr.de/; 2016 [accessed 21 February 2018].

[40] Dobos A, Neises T, Wagner M. Advances in CSP simulation technology in the System Advisor Model. Energy Procedia 2014;49:2482-9. doi:10.1016/j.egypro.2014.03.263.

[41] NREL. System Advisor Model User Documentation, Help Contents. Version 2017.9.5.

[42] DLR. Greenius Help \& Manual Version 4.3.1, 2016.

[43] Kalogirou S. Parabolic Trough Collector System for Low Temperature Steam Generation: Design and Performance Characteristics. Appl Energy 1996;55:119. doi:10.1016/S0306-2619(96)00008-6.

[44] Morin G, Dersch J, Platzer W, Eck M, Häberle A. Comparison of Linear Fresnel 
and Parabolic Trough Collector power plants. Sol Energy 2012;86:1-12. doi:10.1016/j.solener.2011.06.020.

[45] Duffie JA, Beckman WA. Solar Engineering of Thermal Processes. 4th ed. John Wiley \& Sons; 2013.

[46] Dixon SL. Fluid mechanics and thermodynamics of turbomachinery. 4th ed. Butterworth-Heinemann; 1998.

[47] Leyzerovich A. Large steam power turbines. PennWell Publishing Corp; 1997.

[48] Lemmens S. Cost Engineering Techniques and Their Applicability for Cost Estimation of Organic Rankine Cycle Systems. Energies 2016; 9(485). doi:10.3390/en9070485.

[49] Lecompte S, Huisseune H, Van den Broek M, De Schampheleire S, De Paepe M. Part load based thermo-economic optimization of the Organic Rankine Cycle (ORC) applied to a combined heat and power (CHP) system. Appl Energy 2013;111:871-81. doi: 10.1016/j.apenergy.2013.06.043.

[50] Steam turbine, http://www.energy.gov/sites/prod/files/2016/09/f33/CHP-Steam Turbine.pdf; 2016 [accessed 05 March 2018].

[51] Astolfi M, Romano MC, Bombarda P, Macchi E. Binary ORC (Organic Rankine Cycles) power plants for the exploitation of medium low temperature geothermal sources-Part B:Techno-economic optimization. Energy 2014;66:435-46. doi: 10.1016/j.energy.2013.11.057.

[52] Toffolo A, Lazzaretto A, Manente G, Paci M. A multi-criteria approach for the optimal selection of working fluid and design parameters in Organic Rankine 
Cycle $\quad$ systems. Appl Energy 2014;121:219-32. doi:10.1016/j.apenergy.2014.01.089.

[53] Turton R, Bailie RC, Whiting WB, Shaeiwitz JA. Analysis, synthesis and design of chemical processes. 3rd ed. Prentice Hall; 2009.

[54] Bundela PS, Chawla V. Sustainable development through waste heat recovery. Am J Environ Sci 2010;6:83-9. doi: 10.3844/ajessp.2010.83.89.

[55] Quoilin S, Van Den Broek M, Declaye S, Dewallef P, Lemort V. Technoeconomic survey of Organic Rankine Cycle (ORC) systems. Renew Sust Energ Rev 2013;22:168-86. doi: 10.1016/j.rser.2013.01.028.

[56] Pratt\&Whitney. Organic Rankine cycle technology products and applications, https://www.engerati.com/sites/default/files/Day1-1450-David\%20PaulCPA13.pdf; 2013 [accessed 01 November 2018].

[57] National Standard of the People's Republic of China. Steel pressure vessels. GB150-1998.

[58] National Standard of the People's Republic of China. Steel plates for boilers and pressure vessels. GB 713-2008.

[59] Macchi E, Astolfi M. Organic Rankine Cycle (ORC) Power Systems: Technologies and Applications. Woodhead Publishing; 2016.

[60] Hirschberg S, Wiemer S, Burgherr P. Energy from the earth Deep geothermal as a resource for the future? vdf Hochschulverlag AG, an der ETH Zurich; 2014.

[61] Li J. Gradual Progress in the Organic Rankine Cycle and Solar Thermal Power Generation. In: Li J, editors. Structural Optimization and Experimental 
Investigation of the Organic Rankine Cycle for Solar Thermal Power Generation. Springer Theses, Springer; 2015.

[62] Tartière T, Astolfi M. A World Overview of the Organic Rankine Cycle Market. Energy Procedia 2017;129:2-9. doi:10.1016/j.egypro.2017.09.159.

[63] FOB prices of steel products. Shanghai Ganglian E-Commerce Co., Ltd., https://www.mysteel.net/; 2017 [accessed 30 October 2017].

[64] Kurup P, Turchi CS. Parabolic Trough Collector Cost Update for the System Advisor Model (SAM). NREL/TP-6A20-65228; 2015.

[65] LFCs by Beijing TeraSolar Photothermal Technologies Co., Ltd., http://w ww.terasolar.com.cn/; 2018 [accessed 03 February 2018].

[66] Investigation on the economic performance of LFCs, http://www.cspplaza. com/article-11479-2.html; 2018 [accessed 03 February 2018].

[67] Benchmark Feed-in-Tariff policy of solar thermal power industry in China, https://en.cspplaza.com/; 2016 [accessed 01 November 2017].

[68] Leyzerovich A. Wet-steam Turbines for Nuclear Power Plants. American ed. PennWell; 2005.

[69] Zou JM. Analysis on Erosion and Corrosion in QNPC 300MW Turbine. Turbine Technol 2003;45:180-2.

[70] Li J, Gao GT, Pei G, Li PC, Su YH, Ji J, Riffat S. A novel concentrated solar power system using cascade steam-organic Rankine cycle and two-stage accumulators. $\quad$ Energy $\quad$ Procedia $2017 ; 142: 386-94$. doi:10.1016/j.egypro.2017.12.061. 
[71] Kalina J, Świerzewski M, Szega M. Simulation based performance evaluation of biomass fired cogeneration plant with ORC. Energy Procedia 2017;129:660-7. doi:10.1016/j.egypro.2017.09.137.

[72] EnergyPlus. Weather data, https://energyplus.net/weather/; 2017 [accessed 30 October 2017].

[73] Nasruddin, Sholahudin S, Giannetti N, Arnas. Optimization of a cascade refrigeration system using refrigerant $\mathrm{C} 3 \mathrm{H} 8$ in high temperature circuits (HTC) and a mixture of C2H6/CO2in low temperature circuits (LTC). Appl Therm Eng 2016;104:96-103. doi:10.1016/j.applthermaleng.2016.05.059.

[74] Sun ZL, Liang YC, Liu SC, Ji WC, Zang RQ, Liang RZ, Guo ZK. Comparative analysis of thermodynamic performance of a cascade refrigeration system for refrigerant couples R41/R404A and R23/R404A. Appl Energy 2016;184:19-25. doi:10.1016/j.apenergy.2016.10.014.

[75] Cooling naturally, https://www.alfalaval.com/ro/media/stories/district-cooling/ cooling-naturally/; 2017 [accessed 20 February 2018].

[76] Cascade refrigeration system, http://www.nissin-ref.co.jp/english/product_blo g/1-2.html; 2012 [accessed 20 February 2018].

[77] HTRI Software, http://www.htri.net; 2018 [accessed 03 March 2018].

[78] Schack A. Industrial heat transfer: practical and theoretical with basic numerical examples. Springer US; 1965.

[79] Steam Engineering Principles \& Heat Transfer, http://www.spiraxsarco.com /Resources/Pages/Steam-Engineering-Tutorials/steam-engineering-principles-a 
nd-heat-transfer/superheated-steam.aspx; 2018 [accessed 04 March 2018].

[80] ORC solution for geothermal low temperature heat sources, Akca Enerji, Tosunlar Turky (video), http://exergy-orc.com/applications/geothermal; 2009 [accessed 26 February 2018].

[81] Stefánsson V. Investment cost for geothermal power plants. Geothermics 2002;31:263-72. doi:10.1016/S0375-6505(01)00018-9.

[82] Ong S, Campbell C, Denholm P, Margolis R, Heath G. Land-Use Requirements for Solar Power Plants in the United States. NREL/TP-6A20-56290; 2013.

[83] IRENA. Concentrating solar power, https://www.irena.org/Publications/; 2012 [accessed 01 November 2017].

[84] Zhao ZY, Chen YL, Thomson JD. Levelized cost of energy modeling for concentrated solar power projects: A China study. Energy 2017;120:117-27. doi:10.1016/j.energy.2016.12.122.

[85] Gabbrielli R, Castrataro P, Del Medico F, Di Palo M, Lenzo B. Levelized cost of heat for linear Fresnel concentrated solar systems. Energy Procedia 2013;49:1340-9. doi:10.1016/j.egypro.2014.03.143.

[86] NREL. Saguaro Power Plant, https://www.nrel.gov/csp/solarpaces/project_d etail.cfm/projectID=24; 2017 [accessed 01 November 2017].

[87] NREL. Aste 1A, https://www.nrel.gov/csp/solarpaces/project_detail.cfm/proj ectID=215/; 2017 [accessed 01 November 2017]. 


\section{Figure Legends}

Fig.1. Main configurations of direct storage systems for steam power plants, as a combination of storage methods and discharge modes [13-14].

Fig.2. Schematic diagrams of two solar plants: (a) Planta Solar 10 [15]; (b) Puerto Errado 2 [16].

Fig.3. Overview of the work.

Fig.4. DSG solar power system with two-stage accumulators and Rankine cycles.

Fig.5. A few basic modes of the proposed solar system in different time periods.

Fig.6. Flow diagrams for different operating modes: (a) Mode 1; (b) Mode 2; (c) Mode 3; (d) Mode 4.

Fig.7. T-Q diagrams in the HX1: (a) water-benzene; (b) water-pentane; (c) water-water.

Fig. 8. Effect of minimum temperature difference on the temperature of hot side water leaving the HX1.

Fig.9. Scheme of the shell and tube heat exchanger. 


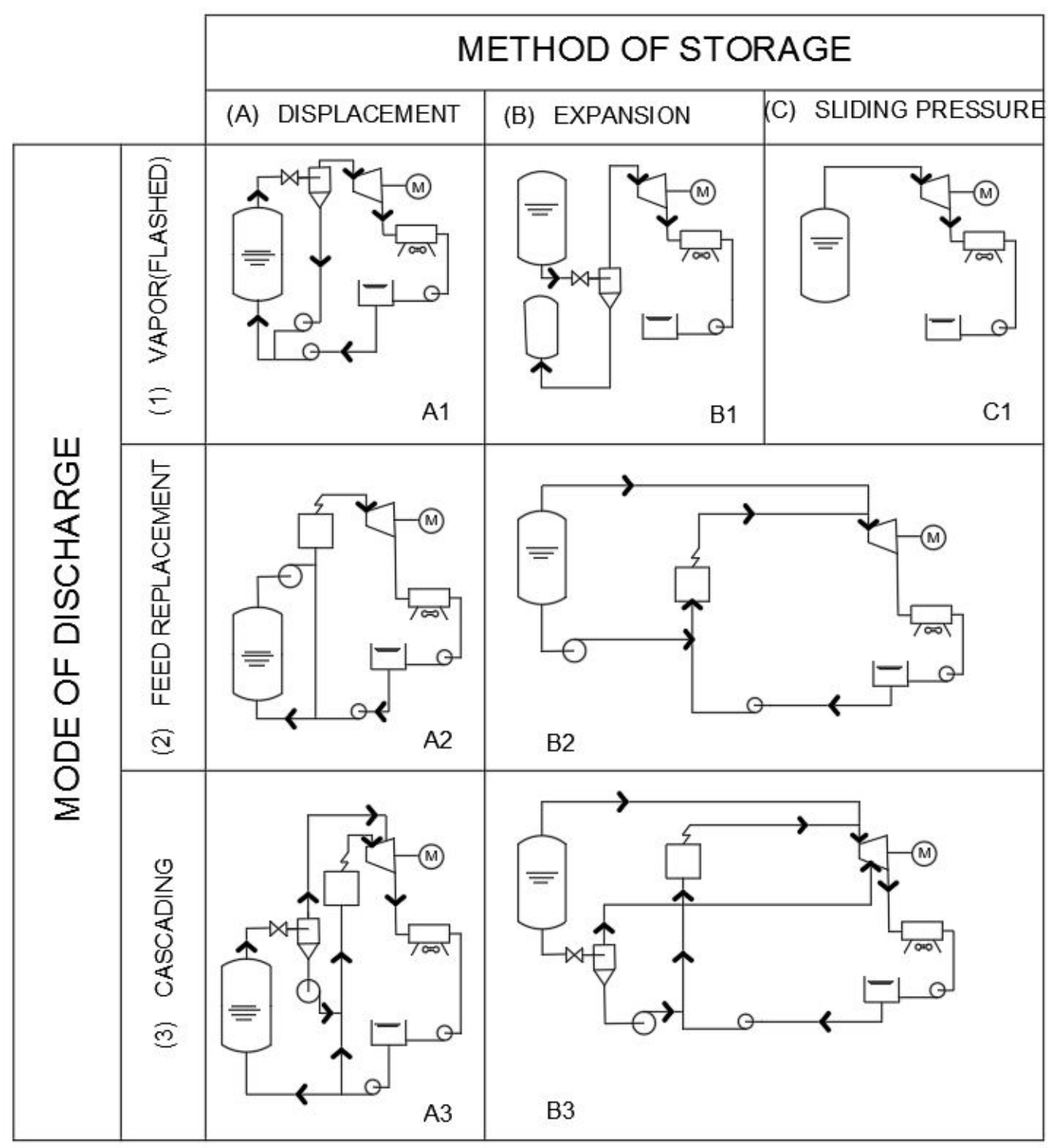

Fig.1. Main configurations of direct storage systems for steam power plants, as a combination of storage methods and discharge modes [13-14]. 


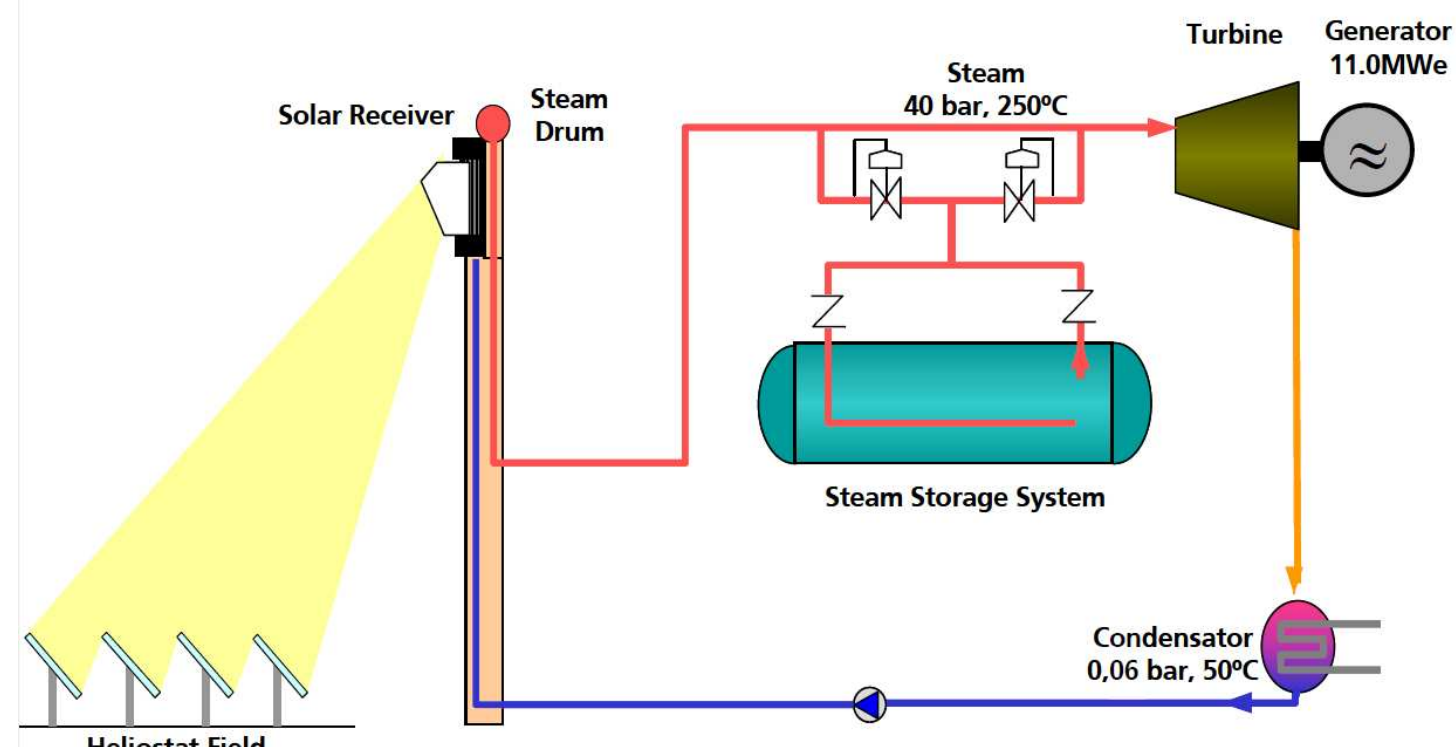

(a)

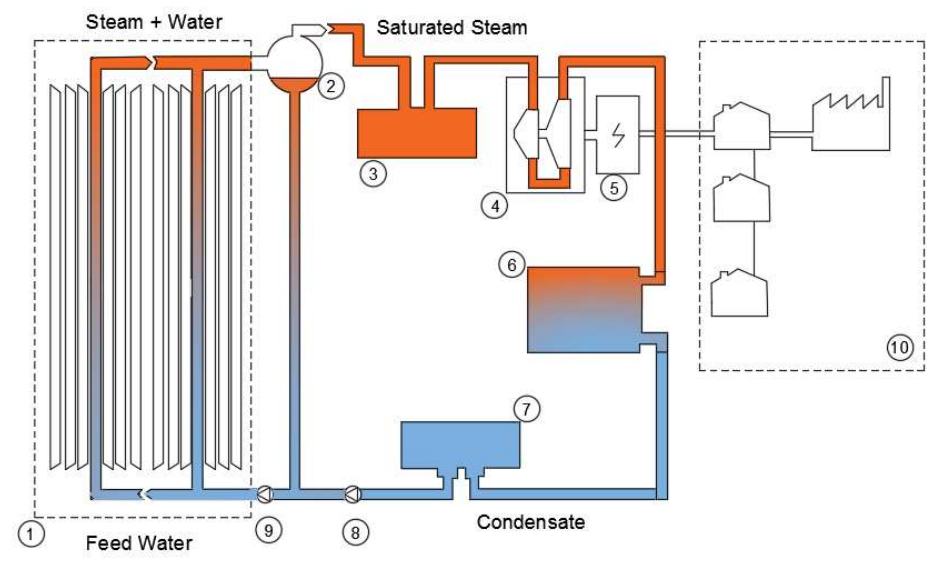

1- Collector Field with Nova1 Module

2- Steam Cylinder

3- Steam Storage

4- Steam Turbine

5- Generator

6- Air cooled condenser

7- Receiver/Feed water tank

8- Feed water pump

9- Re-circulation Pump

10- Public power grid

(b)

Fig.2. Schematic diagrams of two solar plants: (a) Planta Solar 10 [15]; (b) Puerto

Errado 2 [16]. 


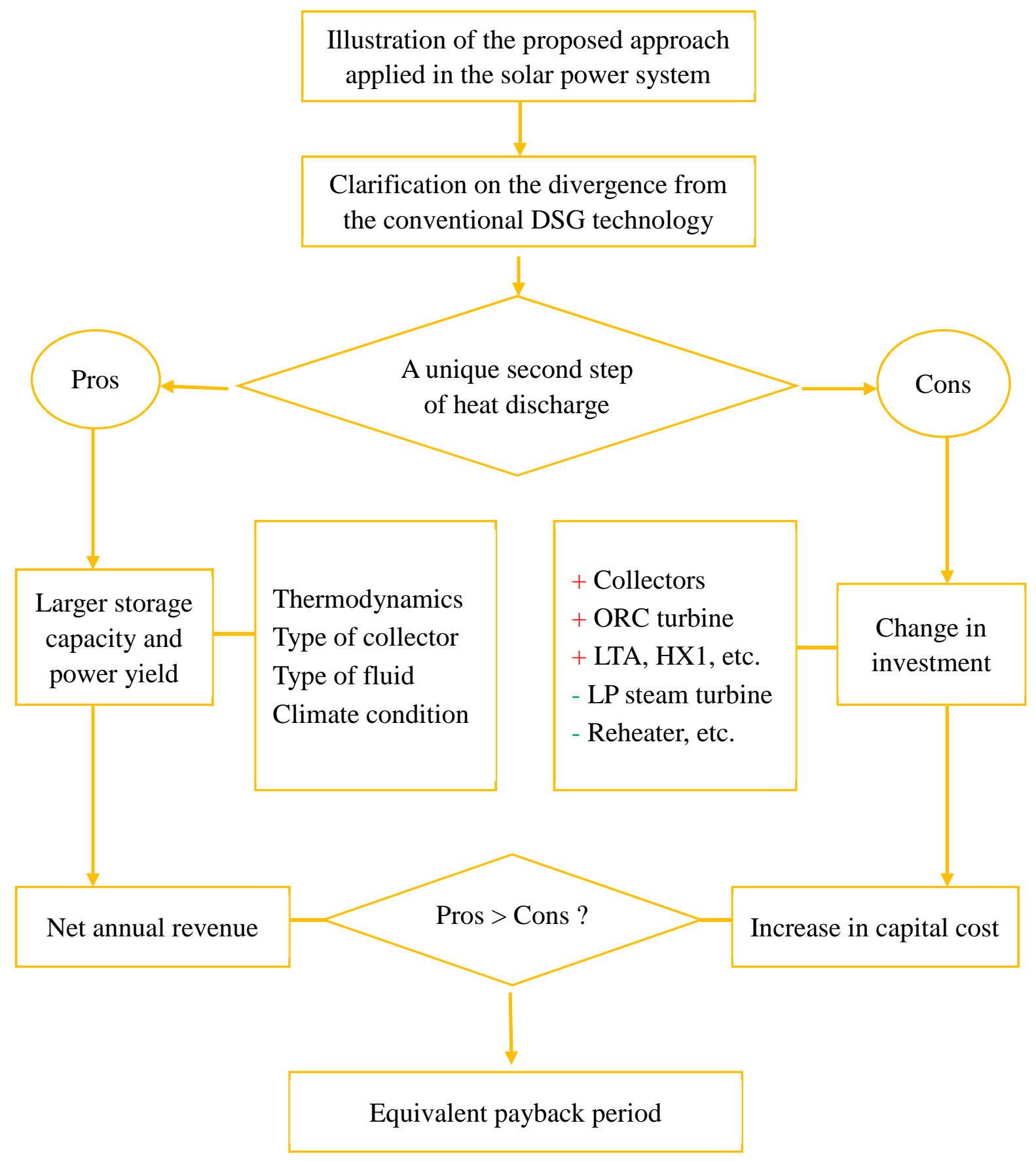

Fig.3. Overview of the work. 


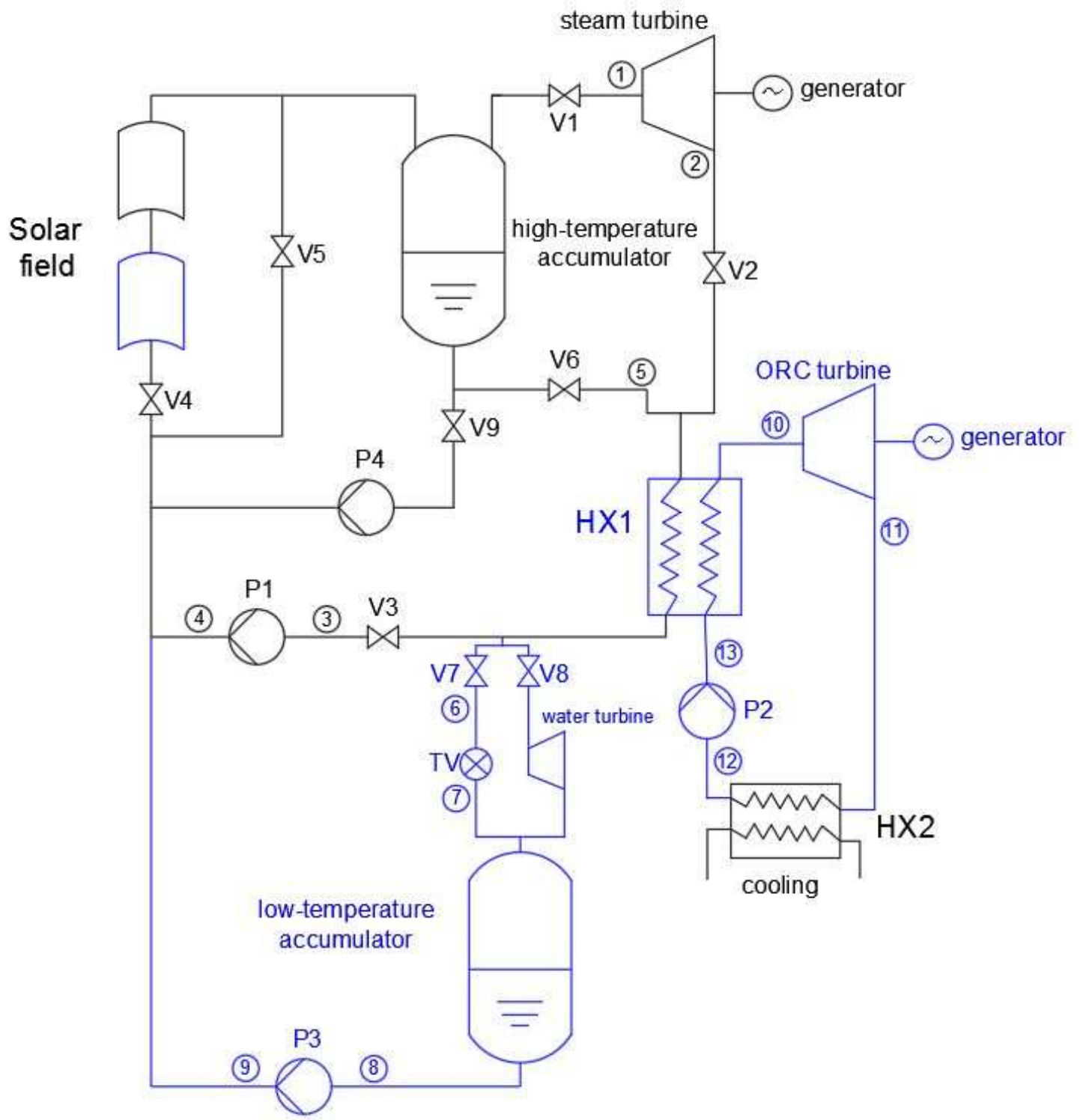

Fig.4. DSG solar power system with two-stage accumulators and Rankine cycles. 


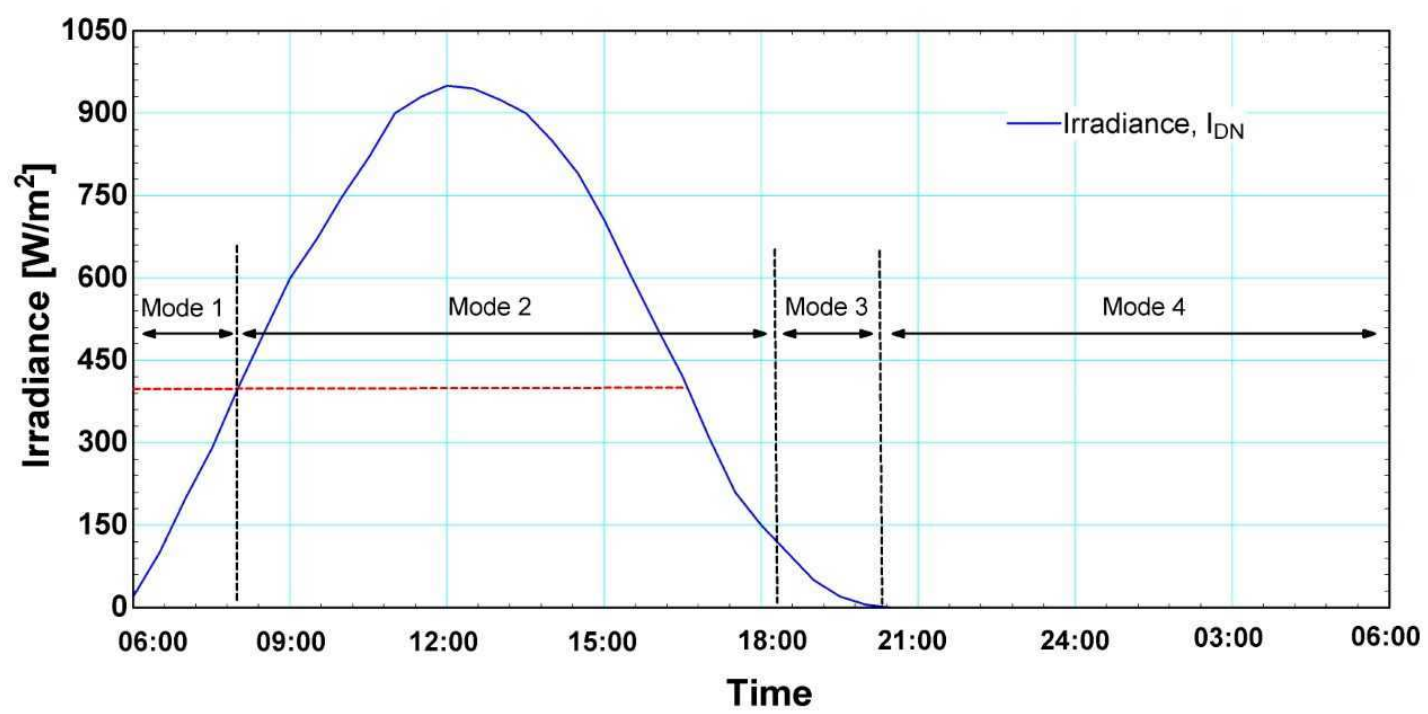

Fig.5. A few basic modes of the proposed solar system in different time periods. 


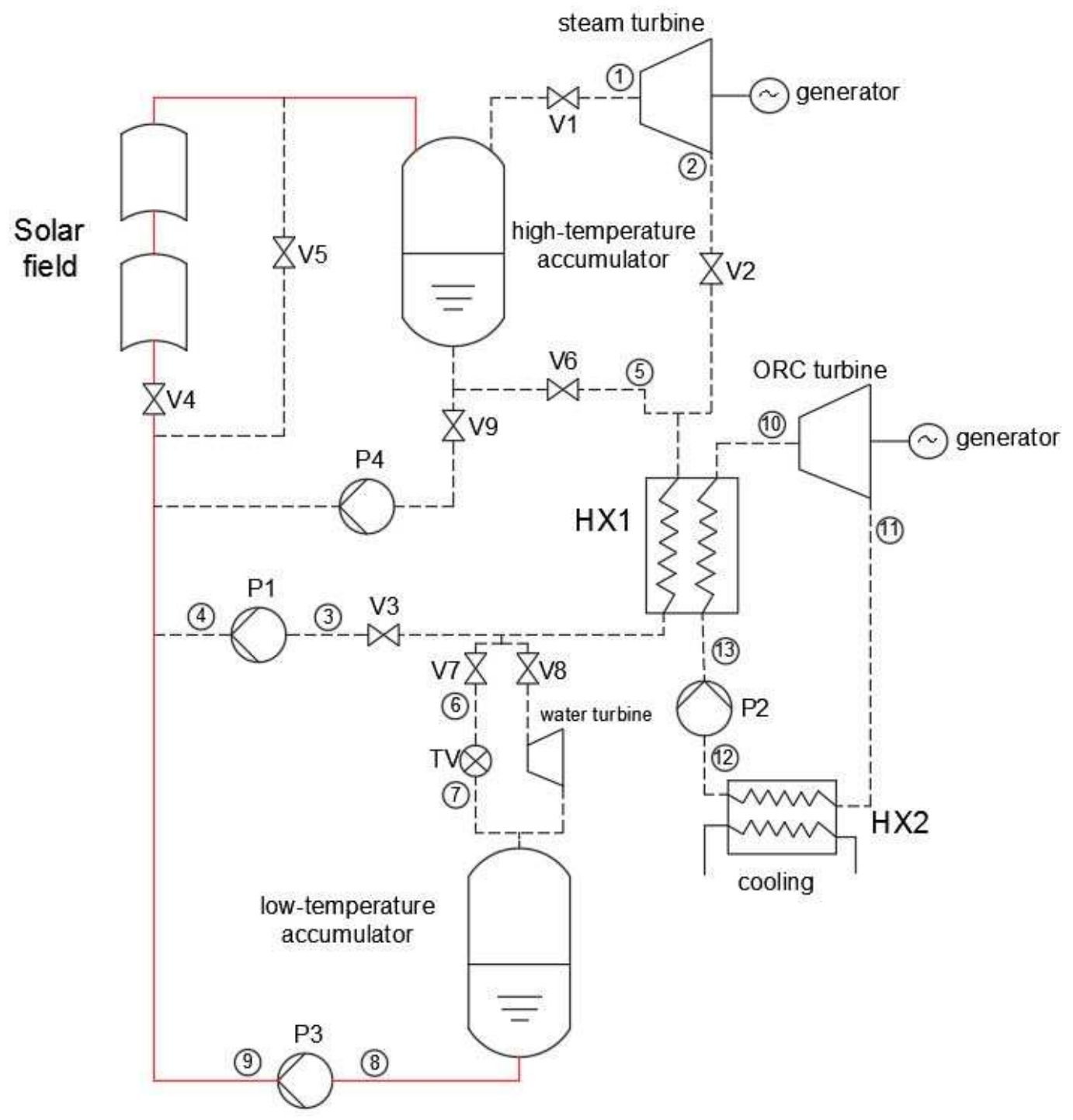

(a) 


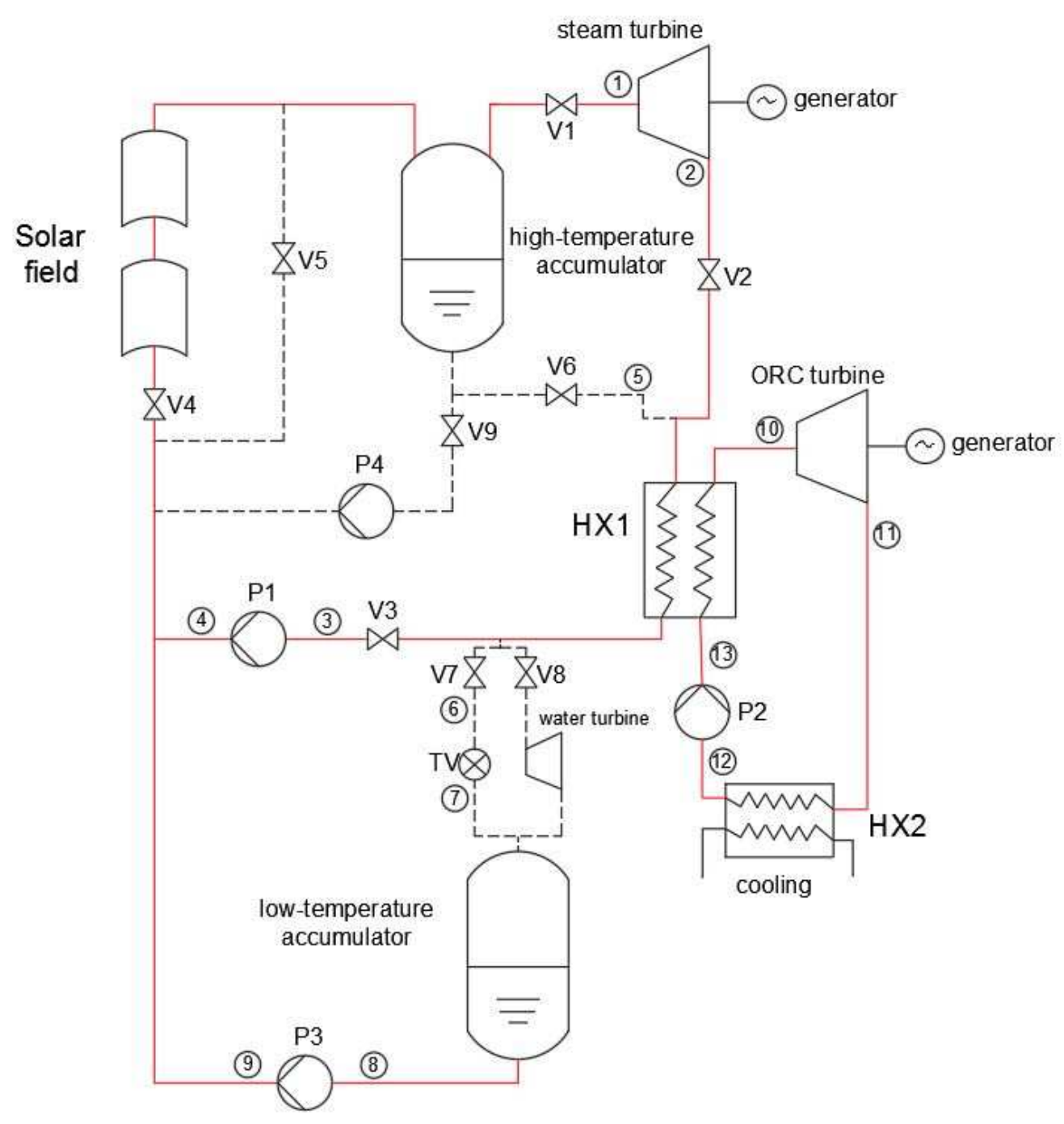

(b) 


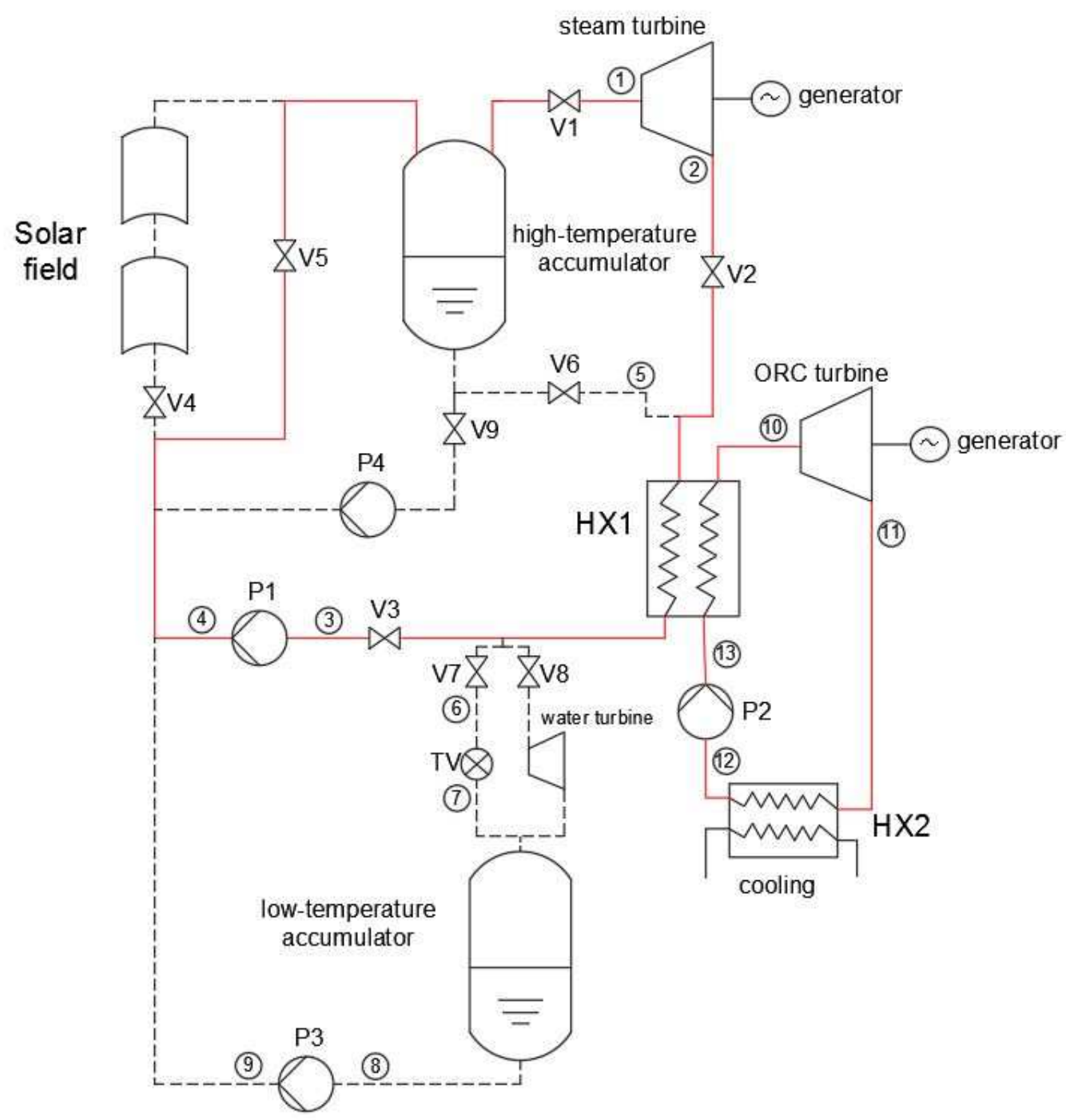

(c) 


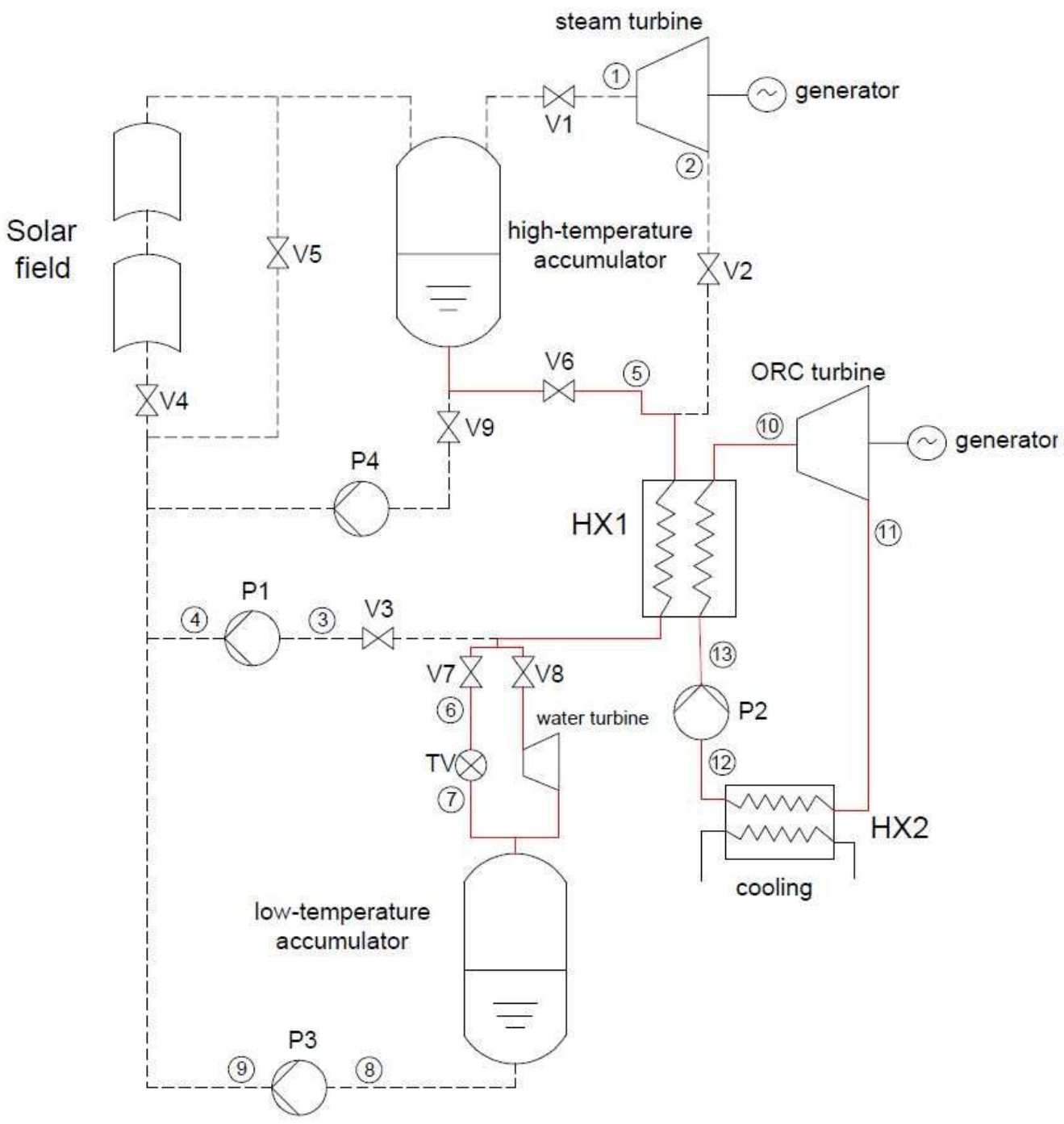

(d)

Fig.6. Flow diagrams for different operating modes: (a) Mode 1; (b) Mode 2; (c)

Mode 3; (d) Mode 4. 


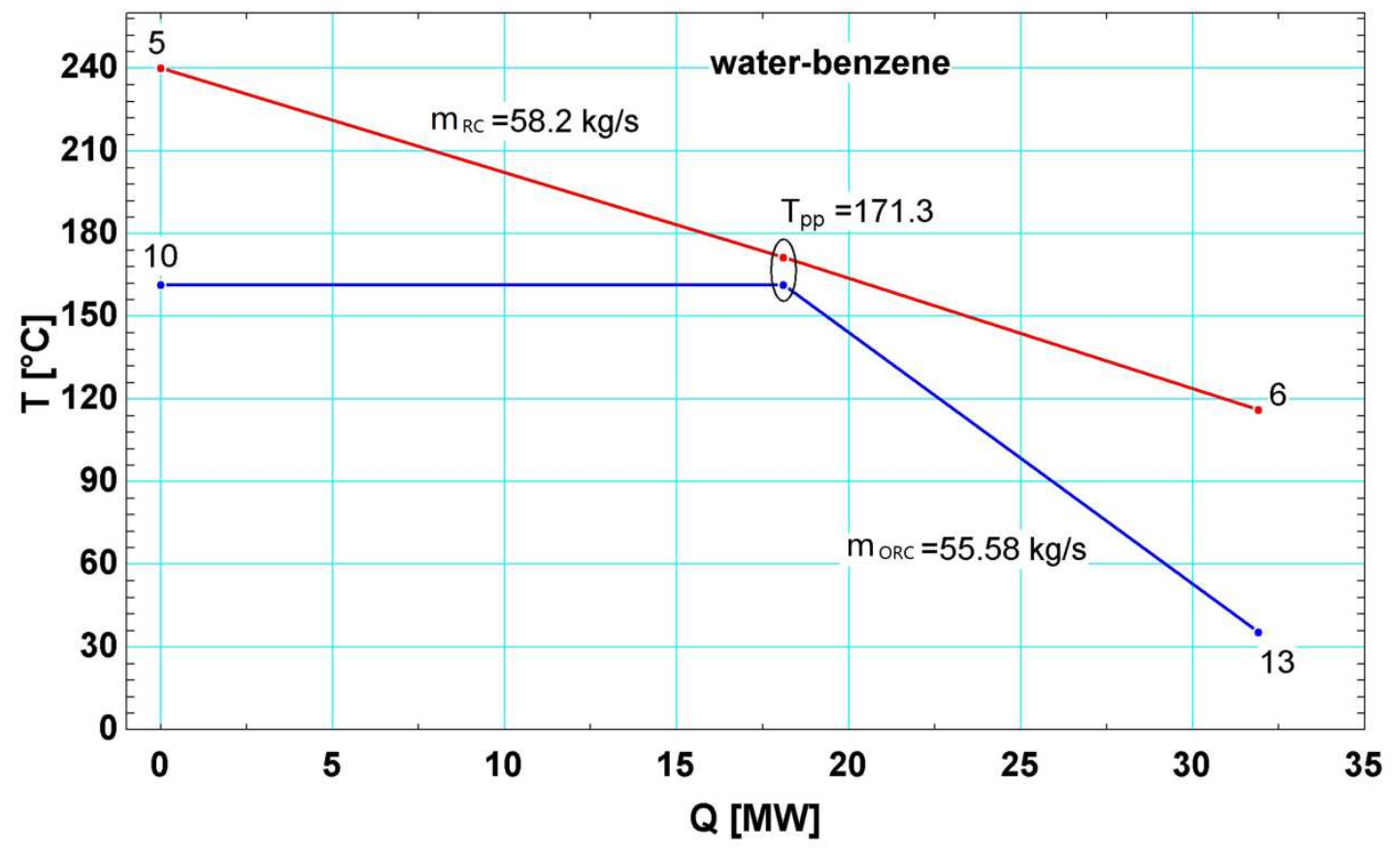

(a)

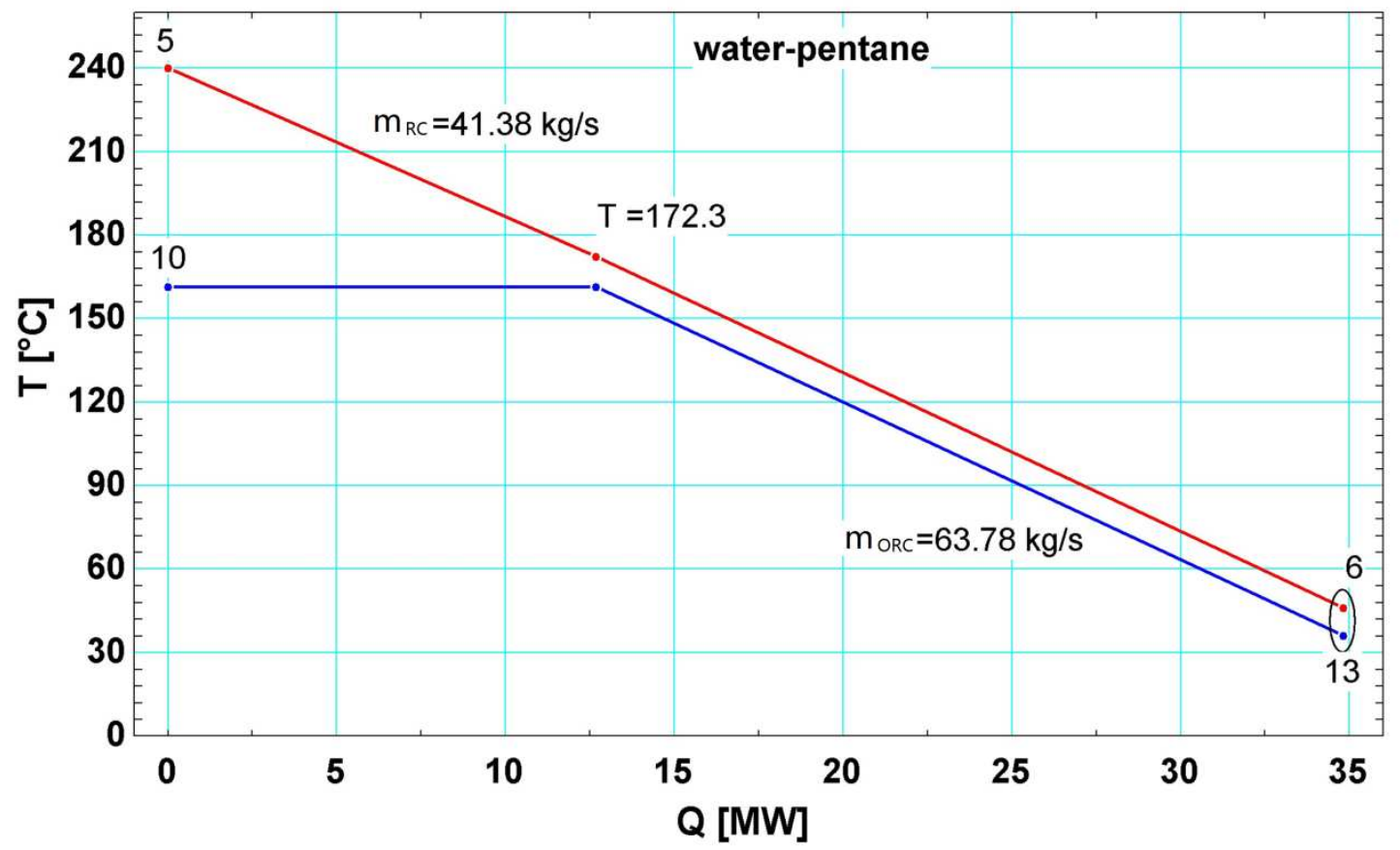

(b) 


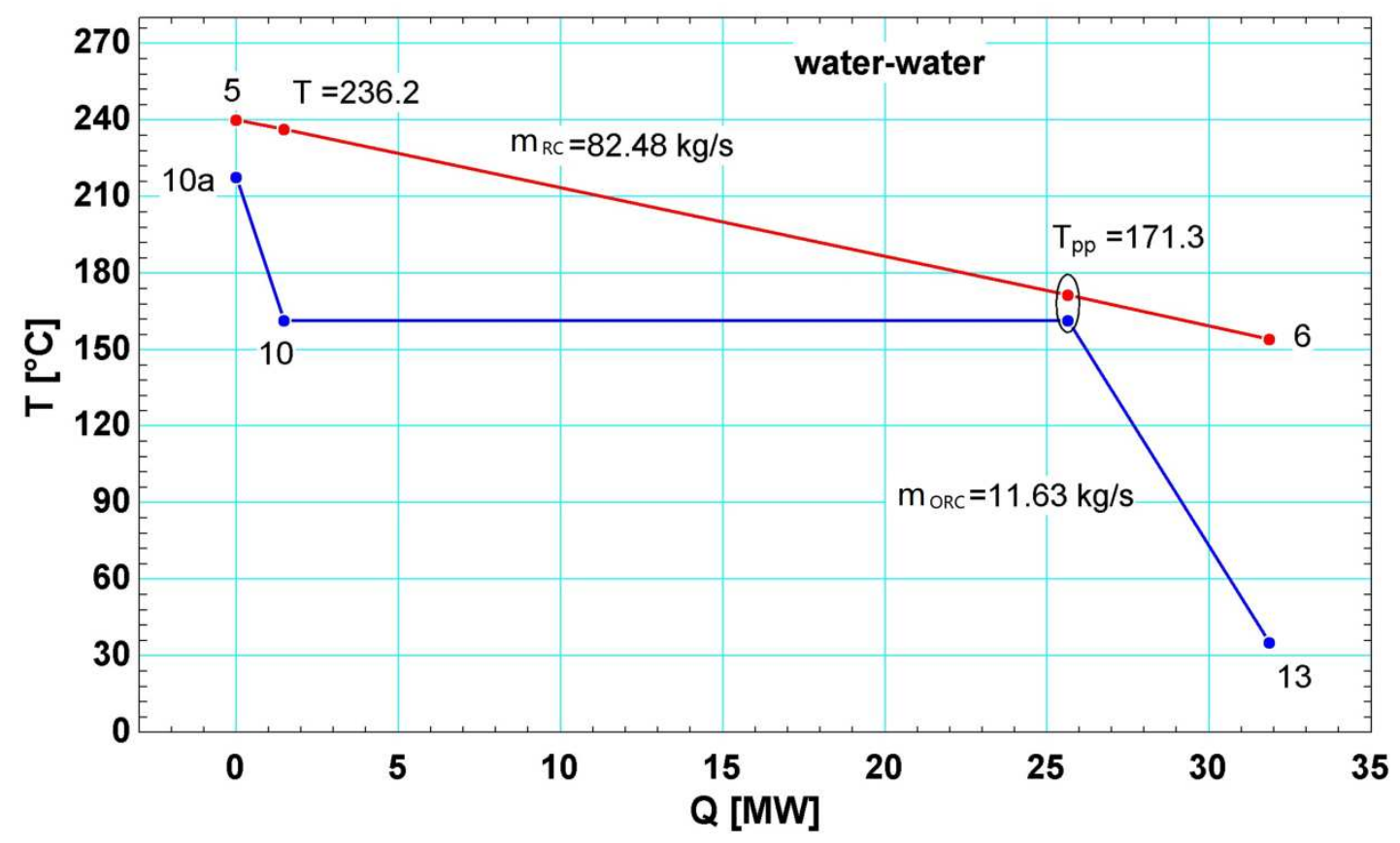

(c)

Fig.7. T-Q diagrams in the HX1: (a) water-benzene; (b) water-pentane; (c) waterwater. 


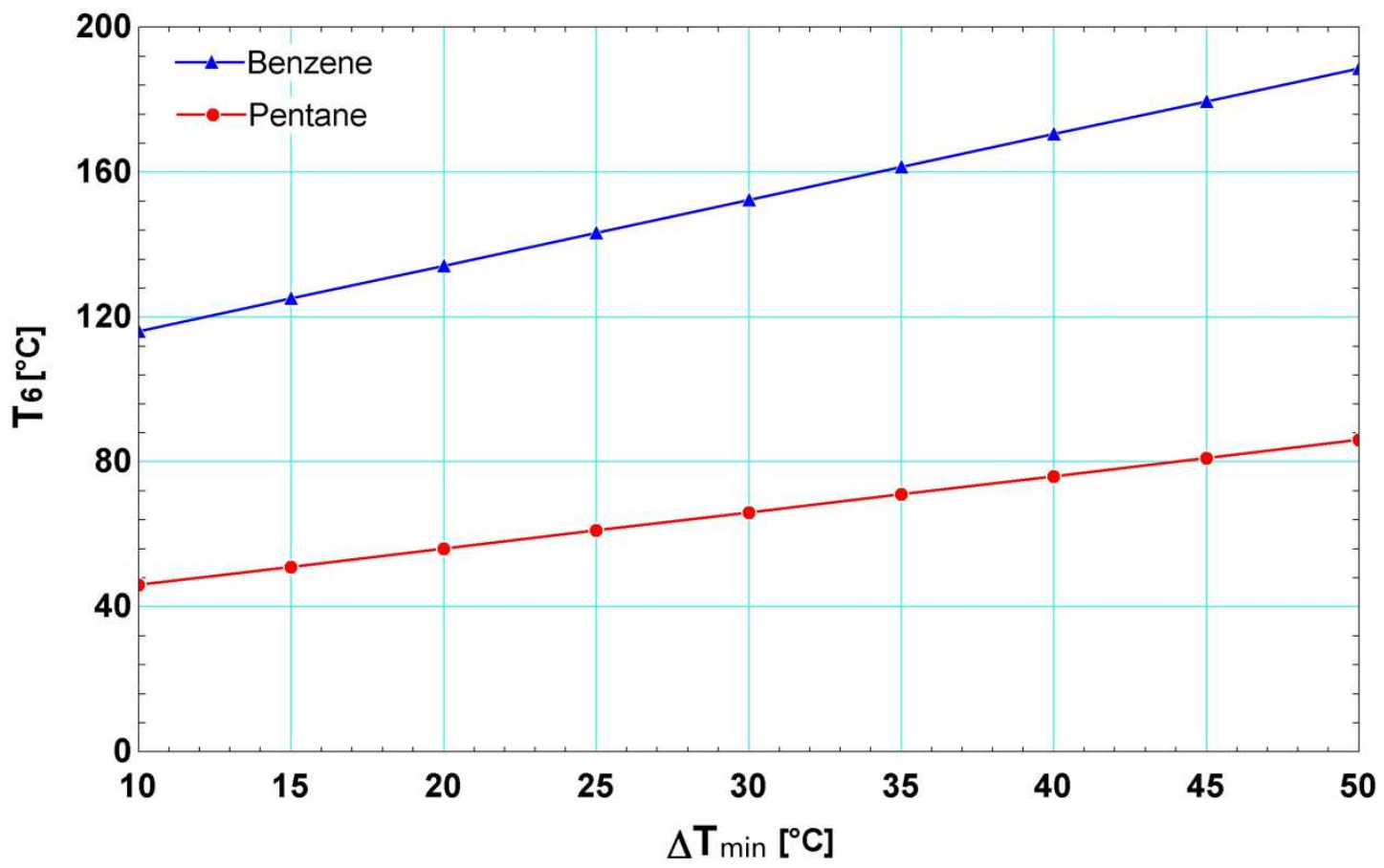

Fig. 8. Effect of minimum temperature difference on the temperature of hot side water leaving the HX1.

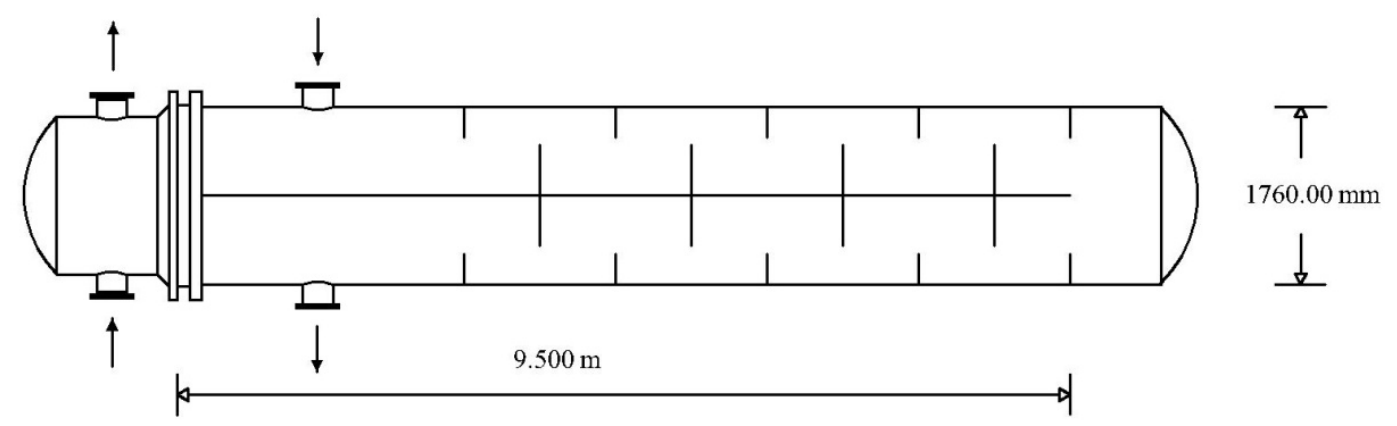

Fig.9. Scheme of the shell and tube heat exchanger. 


\section{Table Legends}

Table 1 A few operational DSG plants worldwide [1].

Table 2 Selected solar ORC plants worldwide [1,30].

Table 3 Specific parameters of PTCs and LFCs in SAM.

Table 4 Incidence angle coefficients in SAM.

Table 5 Specific parameters of PTCs and LFCs in Greenius.

Table 6 Table $6 K_{\text {long }}$ and $K_{\text {trans }}$ in Greenius..

Table 7 Specific parameters for the solar RC-ORC system.

Table 8 Nominal parameters in Qinshan Nuclear Power Plant [69].

Table 9 Parameters of the bottoming cycle under design conditions.

Table 10 Thermodynamic performance in the design conditions.

Table 11 Increased storage capacity using different bottoming cycle fluids.

Table 12 Parameter distribution of hot side water in the second step heat discharge.

Table 13 Collector efficiency in design conditions, unit: $\%$.

Table 14 Additional aperture area of solar collectors and the cost.

Table 15 Parameters of the HX1 in Mode 2.

Table 16 Annual heat gain, unit: $\mathrm{MWh} / \mathrm{m} 2$.

Table 17 Equivalent payback time, unit: year. 
Table 1 A few operational DSG plants worldwide [1].

\begin{tabular}{|c|c|c|c|c|c|c|}
\hline $\begin{array}{l}\text { Project } \\
\text { name }\end{array}$ & Location & Type & $\begin{array}{c}\text { Solar field } \\
\text { temperature } \\
\left({ }^{\circ} \mathrm{C}\right)\end{array}$ & $\begin{array}{c}\text { Steam } \\
\text { pressure } \\
\text { (MPa) }\end{array}$ & Storage & $\begin{array}{r}\text { Power } \\
\text { capacity } \\
\text { (MW) }\end{array}$ \\
\hline Planta Solar 10 & $\begin{array}{l}\text { Sevilla, } \\
\text { Spain }\end{array}$ & $\begin{array}{l}\text { Power } \\
\text { tower }\end{array}$ & $\begin{array}{l}\text { inlet: / } \\
\text { outlet:250-300 }\end{array}$ & 4.5 & $\begin{array}{l}1 \mathrm{~h} \text { steam } \\
\text { accumulator } \\
\text { (Ruths tank) }\end{array}$ & 11.0 \\
\hline Planta Solar 20 & $\begin{array}{l}\text { Sevilla, } \\
\text { Spain }\end{array}$ & $\begin{array}{l}\text { Power } \\
\text { tower }\end{array}$ & $\begin{array}{l}\text { inlet: / } \\
\text { outlet:250-300 }\end{array}$ & 4.5 & $\begin{array}{l}1 \mathrm{~h} \text { steam } \\
\text { accumulator } \\
\text { (Ruths tank) }\end{array}$ & 20.0 \\
\hline Khi Solar One & $\begin{array}{l}\text { Upington, } \\
\text { South Africa }\end{array}$ & $\begin{array}{l}\text { Power } \\
\text { tower }\end{array}$ & $\begin{array}{l}\text { inlet: / } \\
\text { outlet: } 530\end{array}$ & 11 & $\begin{array}{l}2 \mathrm{~h} \text { steam } \\
\text { accumulator }\end{array}$ & 50.0 \\
\hline ISEGS & $\begin{array}{l}\text { Primm, } \\
\text { United States }\end{array}$ & $\begin{array}{l}\text { Power } \\
\text { tower }\end{array}$ & $\begin{array}{l}\text { inlet: } 248 \\
\text { outlet: } 565\end{array}$ & 16.0 & fossil backup & 377.0 \\
\hline Puerto Errado 1 & $\begin{array}{l}\text { Calasparra, } \\
\text { Spain }\end{array}$ & LFC & $\begin{array}{l}\text { inlet:140 } \\
\text { outlet:270 }\end{array}$ & 5.5 & $\begin{array}{c}\text { steam } \\
\text { accumulator } \\
\text { (Ruths tank) }\end{array}$ & 1.4 \\
\hline Puerto Errado 2 & $\begin{array}{l}\text { Calasparra, } \\
\text { Spain }\end{array}$ & LFC & $\begin{array}{l}\text { inlet:140 } \\
\text { outlet:270 }\end{array}$ & 5.5 & $\begin{array}{l}0.5 \mathrm{~h} \text { steam } \\
\text { accumulator } \\
\text { (Ruths tank) }\end{array}$ & 30.0 \\
\hline Thai Solar Energy 1 & $\begin{array}{l}\text { Huai Kachao, } \\
\text { Thailand }\end{array}$ & PTC & $\begin{array}{l}\text { inlet:201 } \\
\text { outlet:340 }\end{array}$ & 3.0 & None & 5.0 \\
\hline
\end{tabular}


Table 2 Selected solar ORC plants worldwide [1,30].

\begin{tabular}{|c|c|c|c|c|c|c|}
\hline $\begin{array}{l}\text { Project } \\
\text { name }\end{array}$ & Location & Type & $\begin{array}{c}\text { Solar field } \\
\text { temperature } \\
\left({ }^{\circ} \mathrm{C}\right)\end{array}$ & $\begin{array}{l}\text { Heat } \\
\text { transfer } \\
\text { fluid }\end{array}$ & Storage & $\begin{array}{r}\text { Power } \\
\text { capacity } \\
\text { (MW) }\end{array}$ \\
\hline $\begin{array}{l}\text { Saguaro Power } \\
\text { Plant }\end{array}$ & $\begin{array}{l}\text { Red Rock, } \\
\text { US }\end{array}$ & PTC & $\begin{array}{l}\text { inlet:120 } \\
\text { outlet:300 }\end{array}$ & $\begin{array}{c}\text { Xceltherm } \\
600\end{array}$ & None & 1.16 \\
\hline $\begin{array}{l}\text { Aalborg CSP- } \\
\text { Brønderslev CSP } \\
\text { with ORC project }\end{array}$ & $\begin{array}{l}\text { Brønderslev, } \\
\text { Denmark }\end{array}$ & PTC & $\begin{array}{l}\text { inlet:252 } \\
\text { outlet:312 }\end{array}$ & water & None & 16.6 \\
\hline $\begin{array}{l}\text { Airlight Energy Ait- } \\
\text { Baha Pilot Plant }\end{array}$ & $\begin{array}{l}\text { Ait Baha, } \\
\text { Morocco }\end{array}$ & PTC & $\begin{array}{l}\text { inlet:270 } \\
\text { outlet:570 }\end{array}$ & $\begin{array}{l}\text { air at } \\
\text { ambient } \\
\text { pressure }\end{array}$ & $\begin{array}{c}5 \text { hours } \\
\text { Packed-bed } \\
\text { of rocks }\end{array}$ & 3.0 \\
\hline $\begin{array}{l}\text { Stillwater GeoSolar } \\
\text { Hybrid Plant }\end{array}$ & $\begin{array}{l}\text { Fallon, } \\
\text { US }\end{array}$ & PTC & l & water & None & 2.0 \\
\hline $\begin{array}{l}\text { eCare Solar } \\
\text { Thermal Project }\end{array}$ & Morocco & LFC & $\begin{array}{l}\text { inlet:160 } \\
\text { outlet:280 }\end{array}$ & water & $\begin{array}{c}2 \text { hours } \\
\text { steam drum }\end{array}$ & 1.0 \\
\hline ENAS Project & $\begin{array}{l}\text { Ottana, } \\
\text { Italy }\end{array}$ & LFC & l & l & I & 0.6 \\
\hline Rende-CSP Plant & $\begin{array}{l}\text { Rende, } \\
\text { Italy }\end{array}$ & LFC & $\begin{array}{l}\text { inlet:- } \\
\text { outlet:280 }\end{array}$ & $\begin{array}{c}\text { diathermic } \\
\text { oil }\end{array}$ & None & 1.0 \\
\hline $\begin{array}{l}\text { IRESEN CSP-ORC } \\
\text { pilot project }\end{array}$ & $\begin{array}{l}\text { Benguerir, } \\
\text { Morocco }\end{array}$ & LFC & $\begin{array}{l}\text { inlet:180 } \\
\text { outlet:300 }\end{array}$ & mineral oil & $\begin{array}{l}1 / 3 \text { hour } \\
\text { buffer }\end{array}$ & 1.0 \\
\hline
\end{tabular}


Table 3 Specific parameters of PTCs and LFCs in SAM.

\begin{tabular}{|c|c|c|}
\hline Terms & PTCs & LFCs \\
\hline Length, $L$ & $150 \mathrm{~m}$ & $44.8 \mathrm{~m}$ \\
\hline Aperture reflective area, $A_{c o l}$ & $817.5 \mathrm{~m}^{2}$ & $513.6 \mathrm{~m}^{2}$ \\
\hline Peak optical efficiency, $\eta_{o p t, 0}$ & $76.77 \%$ & $64.31 \%$ \\
\hline Heat loss coefficient, $a_{0}$ & & 4.05 \\
\hline Heat loss coefficient, $a_{1}$ & & 0.247 \\
\hline Heat loss coefficient, $a_{2}$ & & -0.00146 \\
\hline Heat loss coefficient, $a_{3}$ & & $5.65 e-006$ \\
\hline Heat loss coefficient, $a_{4}$ & & $7.62 \mathrm{e}-008$ \\
\hline Heat loss coefficient, $a_{5}$ & & -1.7 \\
\hline Heat loss coefficient, $a_{6}$ & & 0.0125 \\
\hline
\end{tabular}

Table 4 Incidence angle coefficients in SAM.

\begin{tabular}{|c|c|c|c|c|c|}
\hline$c_{0}$ & 1.00 & $c_{0, \text { long }}$ & 1.003 & $c_{0, \text { trans }}$ & 0.9896 \\
\hline$c_{1}$ & $8.84 \mathrm{e}-4$ & $c_{1, \text { long }}$ & -0.00394 & $c_{1, \text { trans }}$ & $7.68 \mathrm{e}-4$ \\
\hline \multirow[t]{3}{*}{$c_{2}$} & $-5.37 e-5$ & $c_{2, \text { long }}$ & $1.64 \mathrm{e}-4$ & $c_{2, \text { trans }}$ & $-2.20 \mathrm{e}-5$ \\
\hline & & $c_{3, \text { long }}$ & $-8.74 e-6$ & $c_{3, \text { trans }}$ & $-1.24 \mathrm{e}-6$ \\
\hline & & $c_{4, \text { long }}$ & $6.70 e-8$ & $c_{4, \text { trans }}$ & 0 \\
\hline
\end{tabular}


Table 5 Specific parameters of PTCs and LFCs in Greenius.

\begin{tabular}{lll}
\hline Terms & PTCs & LFCs \\
\hline Peak optical efficiency, $\eta_{\text {opt }, 0}$ & $75 \%$ & $63.5 \%$ \\
Mirror cleanliness factor, $\eta_{\text {cleanliness }}$ & 0.97 & 0.97 \\
Heat loss coefficient, $a_{0}$ & 0 & 0 \\
Heat loss coefficient, $a_{1}$ & 0.03298 & 0.032913 \\
Heat loss coefficient, $a_{2}$ & 0 & 0 \\
Heat loss coefficient, $a_{3}$ & 0 & 0 \\
Heat loss coefficient, $a_{4}$ & $1.356 \mathrm{e}-9$ & $1.4838 \mathrm{e}-9$ \\
\hline
\end{tabular}


Table $6 K_{\text {long }}$ and $K_{\text {trans }}$ in Greenius.

\begin{tabular}{|c|c|c|}
\hline $\boldsymbol{\theta}$ & $K_{\text {long }}$ & $\boldsymbol{K}_{\text {trans }}$ \\
\hline 0 & 1 & 1 \\
\hline 5 & 0.96 & 1.04 \\
\hline 10 & 0.94 & 1 \\
\hline 15 & 0.91 & 1.03 \\
\hline 20 & 0.87 & 1 \\
\hline 25 & 0.82 & 1.01 \\
\hline 30 & 0.77 & 1 \\
\hline 40 & 0.64 & 0.96 \\
\hline 50 & 0.48 & 0.95 \\
\hline 60 & 0.31 & 0.78 \\
\hline 70 & 0.14 & 0.55 \\
\hline 80 & 0.02 & 0.3 \\
\hline 90 & 0 & 0.07 \\
\hline
\end{tabular}


Table 7 Specific parameters for the solar RC-ORC system.

\begin{tabular}{|c|c|c|c|}
\hline Term & Value & Term & Value \\
\hline Rated net electricity output, $\dot{w}_{\text {net }}$ & $10 \mathrm{MW}$ & Price of steel [63] & $576 \mathrm{USD} /$ ton \\
\hline Steam turbine efficiency, $\varepsilon_{S T}$ & 0.75 & Price of PTC [64] & $170 \mathrm{USD} / \mathrm{m}^{2}$ \\
\hline ORC turbine efficiency, $\varepsilon_{O T}$ & 0.82 & Price of LFC [65-66] & $120 \mathrm{USD} / \mathrm{m}^{2}$ \\
\hline Generator efficiency, $\varepsilon_{g}$ & 0.95 & Price of electricity [67] & $0.184 \mathrm{USD} / \mathrm{kWh}$ \\
\hline Pump isentropic efficiency, $\varepsilon_{P}$ & 0.75 & Reference wind speed, $v_{w, r e f}$ & $5 \mathrm{~m} / \mathrm{s}$ \\
\hline Minimum temperature & & Reference direct normal solar & \\
\hline & $10^{\circ} \mathrm{C}$ & & $800 \mathrm{~W} / \mathrm{m}^{2}$ \\
\hline difference, $\Delta T_{\min }$ & & irradiation, $I_{D N, r e f}$ & \\
\hline Total volume of HTA & $2500 \mathrm{~m}^{3}$ & Accumulator corrosion allowance & $5 \mathrm{~mm}$ \\
\hline Total volume of LTA & $2500 \mathrm{~m}^{3}$ & Accumulator welding coefficient & 0.8 \\
\hline
\end{tabular}

Table 8 Nominal parameters in Qinshan Nuclear Power Plant [69].

\begin{tabular}{lcll}
\hline Term & Value & Term & Value \\
\hline Mainstream inlet pressure, MPa & 5.345 & LP turbine inlet pressure, MPa & 0.753 \\
Mainstream inlet temperature, ${ }^{\circ} \mathrm{C}$ & 268.2 & LP turbine inlet temperature, ${ }^{\circ} \mathrm{C}$ & $253.6^{*}$ \\
Mainstream inlet quality, $\%$ & 99.5 & LP turbine inlet quality, $\%$ & superheated \\
HP turbine outlet pressure, MPa & 0.817 & LP turbine outlet pressure, MPa & 0.0049 \\
HP turbine outlet temperature, ${ }^{\circ} \mathrm{C}$ & 171.28 & LP turbine outlet temperature, ${ }^{\circ} \mathrm{C}$ & 32.52 \\
HP turbine outlet quality, $\%$ & 87.73 & LP turbine outlet quality, $\%$ & 90.54 \\
\hline
\end{tabular}

* Steam from the HP turbine is reheated before entering the LP turbine 
Table 9 Parameters of the bottoming cycle under design conditions.

\begin{tabular}{|c|c|c|c|c|}
\hline Point & Parameter & Benzene & Pentane & Water \\
\hline \multirow[t]{3}{*}{10} & pressure, $\mathrm{kPa}$ & 728.4 & 1934 & 638.4 \\
\hline & temperature, ${ }^{\circ} \mathrm{C}$ & 161.3 & 161.3 & 161.3 \\
\hline & quality, \% & 100 & 100 & 100 \\
\hline $\mathrm{SH}^{*}$ & pressure, $\mathrm{kPa}$ & N/A & N/A & 638.4 \\
\hline \multirow[t]{3}{*}{$(10 \mathrm{a})$} & temperature, ${ }^{\circ} \mathrm{C}$ & N/A & N/A & 217.6 \\
\hline & quality, \% & N/A & N/A & superheated \\
\hline & & & & steam \\
\hline \multirow[t]{4}{*}{11} & pressure, $\mathrm{kPa}$ & 19.79 & 98.35 & 5.627 \\
\hline & temperature, ${ }^{\circ} \mathrm{C}$ & 66.67 & 87.06 & 35 \\
\hline & quality, \% & superheated & superheated & 90.54 \\
\hline & & vapor & vapor & \\
\hline \multirow[t]{3}{*}{12} & pressure, $\mathrm{kPa}$ & 19.79 & 98.35 & 5.627 \\
\hline & temperature, ${ }^{\circ} \mathrm{C}$ & 35 & 35 & 35 \\
\hline & quality, $\%$ & 0 & 0 & 0 \\
\hline \multirow[t]{4}{*}{13} & pressure, $\mathrm{kPa}$ & 728.4 & 1934 & 638.4 \\
\hline & temperature, ${ }^{\circ} \mathrm{C}$ & 35.33 & 36.07 & 35.07 \\
\hline & quality, $\%$ & subcooled & subcooled & subcooled \\
\hline & & liquid & liquid & liquid \\
\hline
\end{tabular}

* superheater outlet (10a) 
Table 10 Thermodynamic performance in the design conditions.

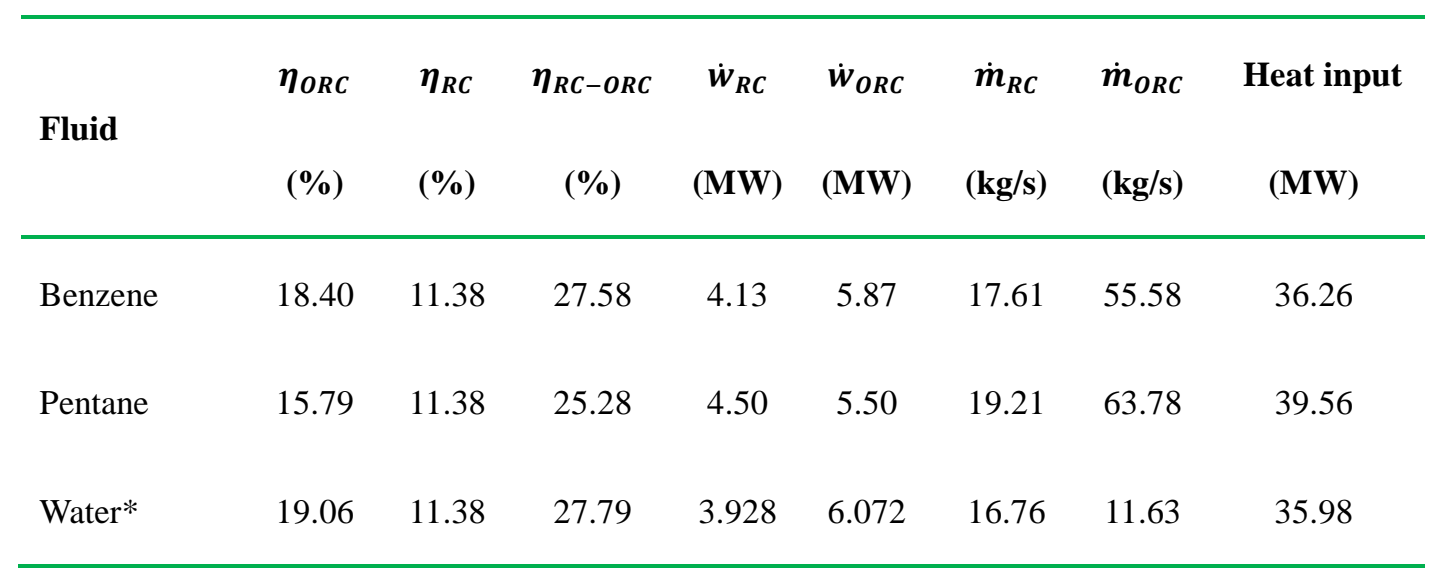

*ORC means the bottoming steam Rankine cycle in the case of water.

Table 11 Increased storage capacity using different bottoming cycle fluids.

\begin{tabular}{|c|c|c|c|c|c|c|c|}
\hline Working & $t_{\text {ORC }}$ & $\dot{m}_{R C, 2 n d}$ & $\dot{m}_{O R C, 2 n d}$ & $\dot{w}_{p 3}$ & $\dot{w}_{\text {loss }}$ & $\eta_{O R C, 2 n d}$ & $W_{2 n d}$ \\
\hline fluid & (h) & $(\mathrm{kg} / \mathrm{s})$ & $(\mathrm{kg} / \mathrm{s})$ & $(\mathbf{k W})$ & $(\mathbf{k W})$ & $(\%)$ & (kWh) \\
\hline Benzene & 9.20 & 58.2 & 55.58 & 425.2 & 194.4 & 17.07 & 50095.3 \\
\hline Pentane & 12.92 & 41.38 & 63.78 & 297.4 & 139.0 & 14.94 & 67254.6 \\
\hline Water & 6.488 & 82.48 & 11.63 & 579.8 & 254.0 & 17.21 & 35633.2 \\
\hline
\end{tabular}

${ }^{*} \dot{\boldsymbol{m}}_{\text {ORC,2nd }}$ is the same as $\dot{m}_{O R C}$ under nominal conditions 
Table 12 Parameter distribution of hot side water in the second step heat discharge.

\begin{tabular}{|c|c|c|c|c|}
\hline \multirow{2}{*}{\multicolumn{2}{|c|}{ Point }} & \multicolumn{3}{|c|}{ Cold side fluid } \\
\hline & & \multirow{2}{*}{$\begin{array}{c}\text { Benzene } \\
3346.9\end{array}$} & \multirow{2}{*}{$\begin{array}{c}\text { Pentane } \\
3346.9\end{array}$} & \multirow{2}{*}{$\begin{array}{c}\text { Water } \\
3346.9\end{array}$} \\
\hline 5 & pressure, $\mathrm{kPa}$ & & & \\
\hline & temperature, ${ }^{\circ} \mathrm{C}$ & 240 & 240 & 240 \\
\hline & quality, $\%$ & 0 & 0 & 0 \\
\hline \multirow[t]{4}{*}{6} & pressure, $\mathrm{kPa}$ & 3346.9 & 3346.9 & 3346.9 \\
\hline & temperature, ${ }^{\circ} \mathrm{C}$ & 116 & 46.43 & 153.9 \\
\hline & quality, \% & subcooled & subcooled & subcooled \\
\hline & & liquid & liquid & liquid \\
\hline \multirow[t]{3}{*}{7} & pressure, $\mathrm{kPa}$ & 174.77 & 10.32 & 528.07 \\
\hline & temperature, ${ }^{\circ} \mathrm{C}$ & 116 & 46.43 & 153.9 \\
\hline & quality, \% & 0.10 & 0.12 & 0.08 \\
\hline \multirow[t]{3}{*}{8} & pressure, $\mathrm{kPa}$ & 174.77 & 10.32 & 528.07 \\
\hline & temperature, ${ }^{\circ} \mathrm{C}$ & 116 & 46.43 & 153.9 \\
\hline & quality, \% & 0 & 0 & 0 \\
\hline \multirow[t]{4}{*}{9} & pressure, $\mathrm{kPa}$ & 5349.7 & 5349.7 & 5349.7 \\
\hline & temperature, ${ }^{\circ} \mathrm{C}$ & 116.85 & 47.04 & 154.85 \\
\hline & quality, $\%$ & subcooled & subcooled & subcooled \\
\hline & & liquid & liquid & liquid \\
\hline
\end{tabular}


Table 13 Collector efficiency in design conditions, unit: $\%$.

\begin{tabular}{|c|c|c|c|c|}
\hline \multirow{2}{*}{$\begin{array}{c}\text { Working } \\
\text { fluid }\end{array}$} & \multicolumn{2}{|c|}{ SAM } & \multicolumn{2}{|c|}{ Greenius } \\
\hline & $\eta_{P T C}$ & $\eta_{L F C}$ & $\eta_{P T C}$ & $\eta_{L F C}$ \\
\hline Benzene & 76.0 & 63.9 & 72.0 & 60.9 \\
\hline Pentane & 76.1 & 64.0 & 72.2 & 61.1 \\
\hline
\end{tabular}


Table 14 Additional aperture area of solar collectors and the cost.

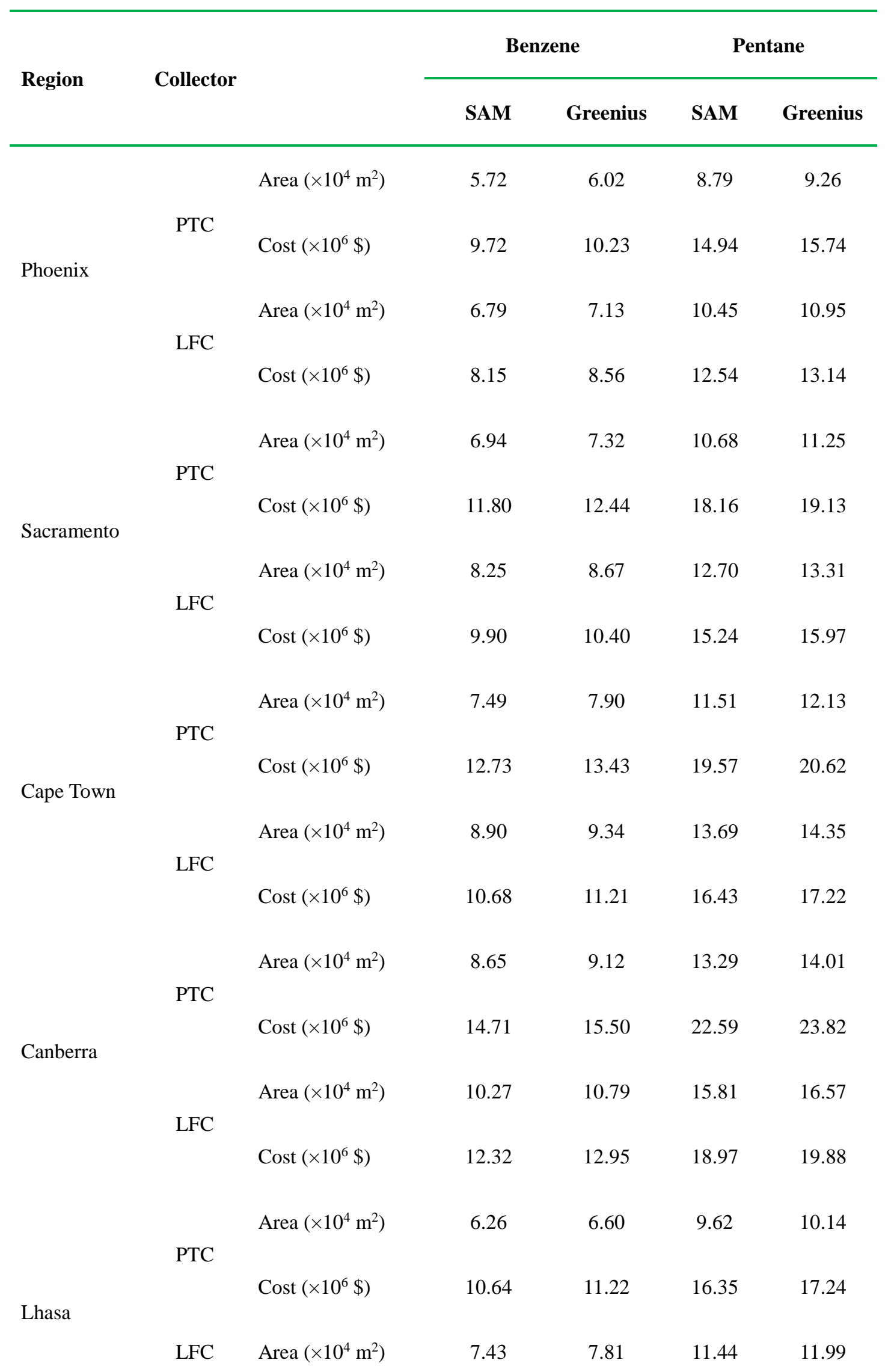




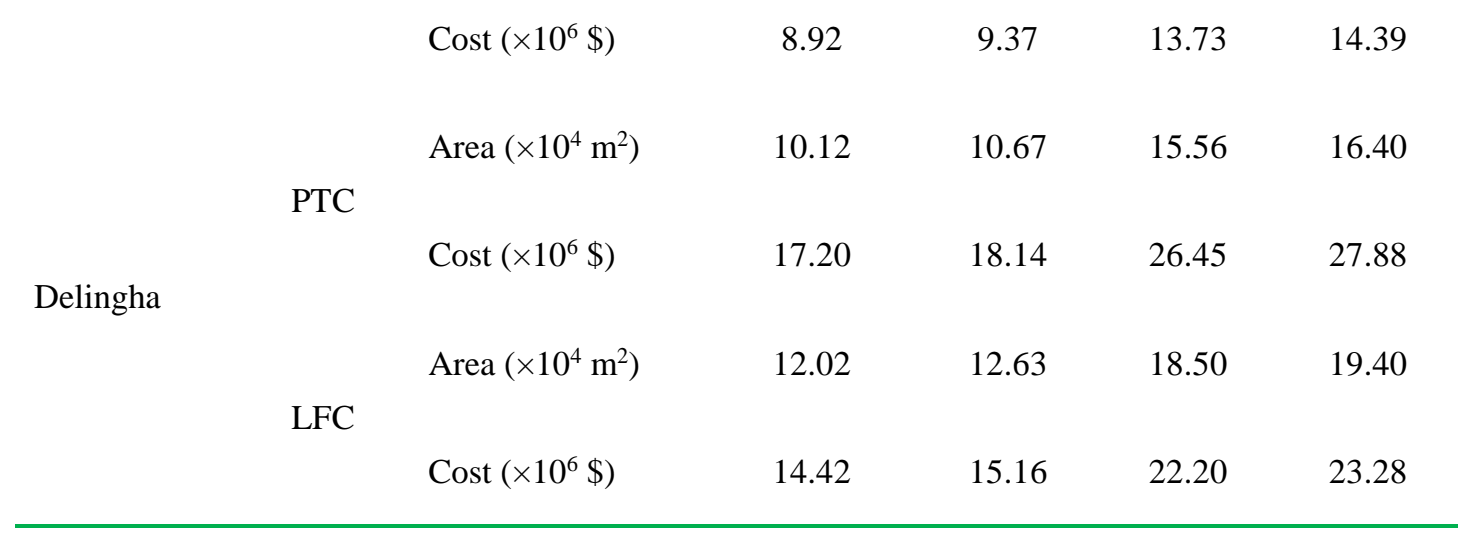


Table 15 Parameters of the HX1 in Mode 2.

\begin{tabular}{|c|c|c|c|c|}
\hline \multirow{2}{*}{ Process data } & \multicolumn{2}{|c|}{ Hot shell side } & \multicolumn{2}{|c|}{ Cold tube side } \\
\hline & Inlet & Outlet & Inlet & Outlet \\
\hline Temperature, ${ }^{\circ} \mathrm{C}$ & 170.97 & 170.10 & 36 & 161.87 \\
\hline Pressure, $\mathrm{kPa}$ & 811 & 794 & 2000 & 1985 \\
\hline Quality, \% & 88.6 & 0 & subcooled & 100 \\
\hline Mass flow rate, $\mathrm{kg} / \mathrm{s}$ & 19.21 & & 63.78 & \\
\hline Velocity, $\mathrm{m} / \mathrm{s}$ & 12.4 & & 1.51 & \\
\hline \multicolumn{2}{|c|}{ Overall heat transfer coefficient, $\mathrm{W} / \mathrm{m}^{2 \circ} \mathrm{C}$} & \multicolumn{2}{|r|}{1048.18} & \\
\hline \multicolumn{2}{|c|}{ Effective overall temperature difference, ${ }^{\circ} \mathrm{C}$} & \multicolumn{2}{|r|}{18.0} & \\
\hline Total heat, MW & & \multicolumn{2}{|r|}{36} & \\
\hline
\end{tabular}


Table 16 Annual heat gain, unit: $\mathrm{kWh} / \mathrm{m}^{2}$.

\begin{tabular}{lcccccccc}
\hline & \multicolumn{3}{c}{ Benzene } & \multicolumn{5}{c}{ Petane } \\
\cline { 2 - 9 } Regions & \multicolumn{2}{c}{ SAM } & \multicolumn{2}{c}{ Greenius } & SAM & \multicolumn{2}{c}{ Greenius } \\
\cline { 2 - 9 } & PTC & LFC & PTC & LFC & PTC & LFC & PTC & LFC \\
\hline Phoenix & 1639 & 1110 & 1531 & 1033 & 1644 & 1112 & 1538 & 1040 \\
Sacramento & 1301 & 876 & 1214 & 813 & 1306 & 878 & 1221 & 819 \\
Cape Town & 1252 & 901 & 1170 & 836 & 1257 & 904 & 1176 & 842 \\
Canberra & 1144 & 792 & 1067 & 731 & 1149 & 794 & 1074 & 738 \\
Lhasa & 1319 & 913 & 1230 & 844 & 1323 & 915 & 1237 & 850 \\
Delingha & 905 & 613 & 841 & 553 & 911 & 615 & 849 & 560 \\
\hline
\end{tabular}


Table 17 Equivalent payback time, unit: year.

\begin{tabular}{|c|c|c|c|c|c|c|c|c|}
\hline \multirow{3}{*}{ Regions } & \multicolumn{4}{|c|}{ Benzene } & \multicolumn{4}{|c|}{ Petane } \\
\hline & \multicolumn{2}{|c|}{$\mathbf{S A M}$} & \multicolumn{2}{|c|}{ Greenius } & \multicolumn{2}{|c|}{ SAM } & \multicolumn{2}{|c|}{ Greenius } \\
\hline & PTC & LFC & PTC & LFC & PTC & LFC & PTC & LFC \\
\hline Phoenix & 3.38 & 3.54 & 3.62 & 3.80 & 3.82 & 4.00 & 4.08 & 4.27 \\
\hline Sacramento & 4.25 & 4.46 & 4.54 & 4.81 & 4.80 & 5.05 & 5.12 & 5.41 \\
\hline Cape Town & 4.40 & 4.33 & 4.71 & 4.67 & 4.98 & 4.90 & 5.32 & 5.26 \\
\hline Canberra & 4.81 & 4.92 & 5.14 & 5.32 & 5.44 & 5.57 & 5.81 & 5.99 \\
\hline Lhasa & 4.20 & 4.29 & 4.49 & 4.64 & 4.74 & 4.85 & 5.06 & 5.22 \\
\hline Delingha & 6.06 & 6.33 & 6.51 & 7.02 & 6.85 & 7.17 & 7.35 & 7.87 \\
\hline
\end{tabular}




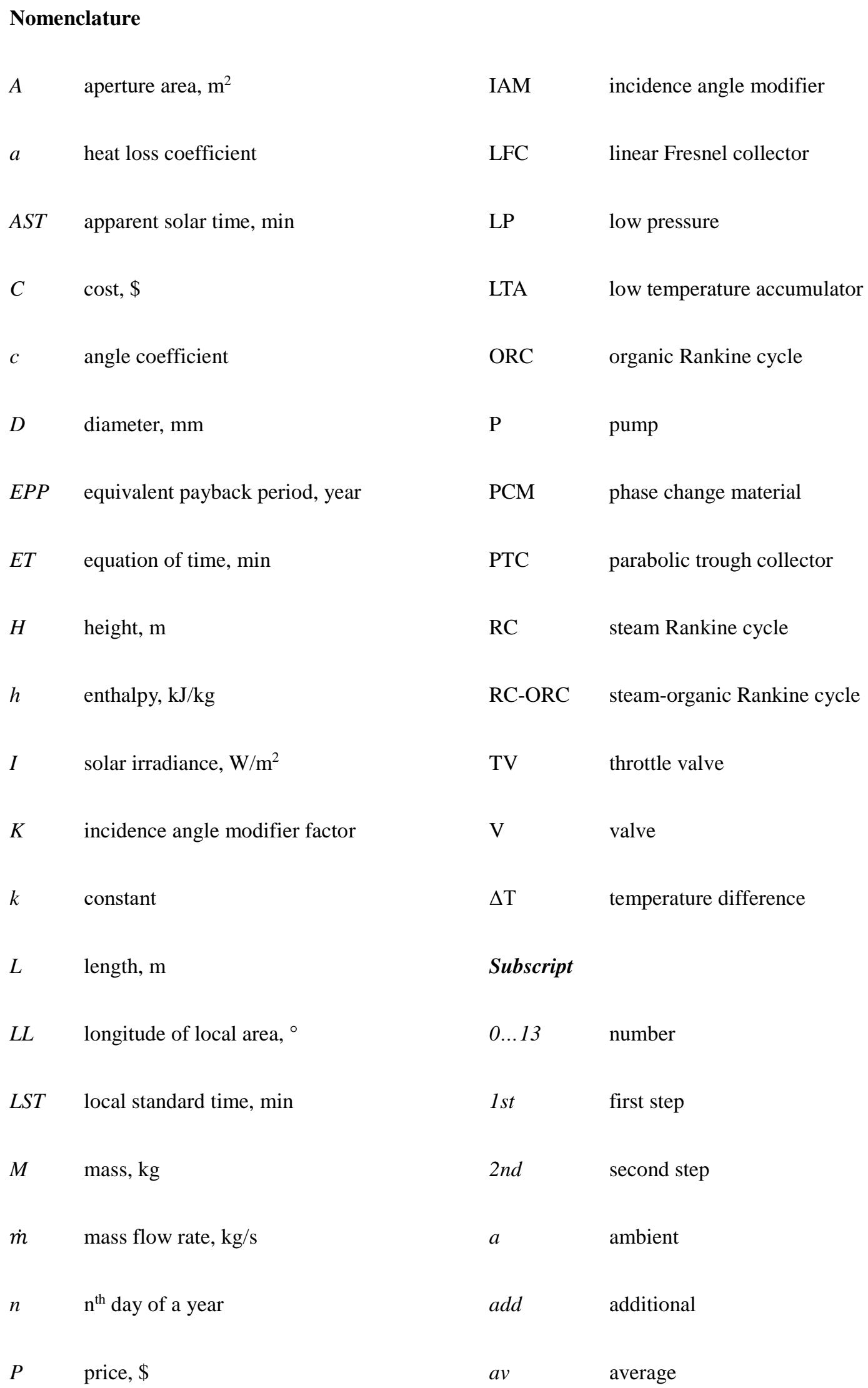




\begin{tabular}{|c|c|c|c|}
\hline$p$ & pressure, $\mathrm{MPa}$ & cleanliness & mirror cleanliness factor \\
\hline$Q$ & heat, kJ & col & collector \\
\hline$q$ & receiver heat loss, $\mathrm{W} / \mathrm{m}$ & $c y$ & cylinder \\
\hline$S L$ & standard meridian for local time zone, ${ }^{\circ}$ & $D N$ & direct normal \\
\hline$T$ & temperature, ${ }^{\circ} \mathrm{C}$ & $e$ & electricity \\
\hline$t$ & time, $\mathrm{h}$ & $g$ & generator \\
\hline$V$ & volume, $\mathrm{m}^{3}$ & head & head \\
\hline$v$ & speed, $\mathrm{m} / \mathrm{s}$ & $i$ & diameter \\
\hline$W$ & work, $\mathrm{kJ}$ & in & inlet \\
\hline$\dot{w}$ & work, $\mathrm{kW}$ & $l$ & heat loss \\
\hline$Y$ & yield, \$ & long & longitudinal angle \\
\hline$\alpha$ & 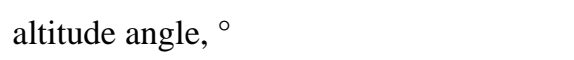 & loss & heat loss \\
\hline$\gamma$ & azimuth angle, ${ }^{\circ}$ & & power loss \\
\hline$\delta$ & solar declination, ${ }^{\circ}$ & $\min$ & minimum \\
\hline & thickness, mm & net & net power \\
\hline$\varepsilon$ & device efficiency, $\%$ & $O T$ & ORC turbine \\
\hline$\eta$ & system efficiency, \% & opt & optical \\
\hline$\theta$ & incidence angle, $^{\circ}$ & out & outlet \\
\hline$\rho$ & density, $\mathrm{kg} / \mathrm{m}^{3}$ & $P$ & pump \\
\hline$[\sigma]^{t}$ & permissible stress, $\mathrm{MPa}$ & rated & nominal value \\
\hline$\phi$ & geographic latitude, ${ }^{\circ}$ & ref & reference \\
\hline & welding coefficient & $S T$ & steam turbine \\
\hline
\end{tabular}




\begin{tabular}{|llll|}
\hline \multicolumn{1}{|l}{ Abbreviation } & $s$ & isentropic \\
CSP & concentrating solar power & & solar \\
DSG & direct steam generation & steel & steel \\
HP & high pressure & $T$ & thermal \\
HTA & high temperature accumulator & trans & transverse angle \\
HX & heat exchanger & $w$ & water \\
\hline
\end{tabular}

